Revista Brasil. Bot., V.34, n.1, p.1-19, jan.-mar. 2011

\title{
Eunotiaceae (Eunotiales, Bacillariophyta) em ambientes lacustres na Planície Costeira do Sul do Brasil ${ }^{1}$
}

\author{
ALINE BRUGALLI BICCA², LEZILDA CARVALHO TORGAN ${ }^{2,3} \mathrm{e}$ \\ CRISTIANE BAHI DOS SANTOS ${ }^{2}$
}

(recebido: 20 de janeiro de 2010; aceito: 04 de novembro de 2010)

\begin{abstract}
Eunotiaceae (Eunotiales, Bacillariophyta) in lacustrine environments in the Coastal Plain from South of Brazil). The Eunotiaceae study in several environments (lakes, swamps and dams) in the Costal Plain of Rio Grande do Sul State was carried out in the autumn and the spring of 2003. Twenty six specific and infra-specific taxa were identified, one belonging to Actinella and twenty five to Eunotia. The highest richness of Eunotia species was reported in the swamps where we found a lush marginal vegetation and more acid water ( $\mathrm{pH} \mathrm{4,3}$ and 5,4). Eunotia bilunaris (Ehr.) Souza, E. tridentula Ehr. var. tridentula, E. vumbae Choln., E. yberai Freng. and E. zygodon Ehr. are new records for the Coastal Plain of Southern Brazil. The species are described, commented, and illustrated in light microscope (LM) and/or in scanning electron microscope (SEM).
\end{abstract}

Key words - diatoms, geographical distribution, subtropical climate, taxonomy

RESUMO - (Eunotiaceae (Eunotiales, Bacillariophyta) em ambientes lacustres na Planície Costeira do Sul do Brasil). O estudo da família Eunotiaceae em diferentes ambientes (lagoas, banhados e açude) na Planície Costeira do Rio Grande do Sul foi realizado no outono e primavera de 2003. Foram identificados 26 táxons específicos e infra-específicos, um pertencente ao gênero Actinella e 25 a Eunotia. A maior riqueza de espécies de Eunotia foi registrada nos banhados, onde a vegetação marginal foi mais abundante e as águas mais ácidas (pH 4,3 e 5,4). Eunotia bilunaris (Ehr.) Souza, E. tridentula Ehr. var. tridentula, E. vumbae Choln., E. yberai Freng. e E. zygodon Ehr. tratam-se de primeiras citações para a Planície Costeira do sul do Brasil. As espécies são descritas, comentadas e ilustradas em microscopio óptico (MO) e/ou em microscópio eletrônico de varredura (MEV).

Palavras-chave - clima subtropical, diatomáceas, distribuição geográfica, taxonomia

\section{Introdução}

Eunotiaceae inclui os gêneros Actinella Lewis, Amphicampa (Ehrenberg) Ralfs, Eunophora Vyverman, Sabbe \& Mann, Eunotia Ehrenberg e Semiorbis Patrick (Kociolek \& Spaulding 2003) além de Amphorotia D.M Williams \& Reid e Perinotia Metzeltin \& Lange-Bertalot recentemente descritos (Williams \& Reid 2006, Metzeltin \& Lange-Bertalot 2007). Semiorbis e Amphicampa são raros e monoespecíficos, cuja distribuição limita-se a ambientes montanhosos da América do Norte (Round et al. 1990) e águas alcalinas dos Estados Unidos (Kociolek 2000), respectivamente. Eunophora ocorre em lagos distróficos e oligotróficos na Tasmânia e Nova Zelândia; Amphorotia esta associado a águas marinhas e salobras com representantes na Sibéria, Mongólia e China e Perinotia é original da região semi-árida

1. Parte da Dissertação de mestrado do primeiro autor, Programa de Pós-Graduação em Botânica, Instituto de Biociências, Universidade Federal do Rio Grande do Sul, Porto Alegre, RS, Brasil.

2. Fundação Zoobotânica do Rio Grande do Sul, Museu de Ciências Naturais, Rua Dr. Salvador França, 1427, 90690-000 Porto Alegre, RS, Brasil.

3. Autor para correspondência: lezilda-torgan@fzb.rs.gov.br tropical do Brasil (Williams \& Reid 2006, Metzeltin \& Lange-Bertalot 2007).

Actinella é comum em águas ácidas de regiões tropicais, principalmente na região Amazônica, que parece ser o centro de sua dispersão (Kociolek et al. 2001), e Eunotia é cosmopolita, com algumas espécies que se limitam a regiões tropicais e subtropicais do globo (Metzeltin \& Lange-Bertalot 1998).

Dentre os gêneros mencionados, somente Actinella e Eunotia foram encontrados na Planície Costeira do Rio Grande do Sul. Nesse estado, estudos envolvendo esses dois gêneros tiveram início com Zimmermann (1916). Posteriormente, a partir da década de 70, foram realizados vários inventários florísticos, na sua maioria desenvolvidos em ambientes lênticos da região da Depressão Central e região norte da Planície Costeira, sendo registrados duas espécies de Actinella e 96 táxons específicos e infra-específicos de Eunotia (Torgan et al. 1999).

No Workshop de Avaliação de Ações Prioritárias para as Zonas Costeira e Marinha, realizado em outubro de 2002 pelo Ministério do Meio Ambiente, foram indicadas duas áreas no Rio Grande do Sul como prioritárias para estudo: a da Lagoa do Casamento, por 
ser insuficientemente conhecida, e a do Butiazal de Tapes, pela sua extrema importância biológica. No levantamento preliminar da microflora dessas áreas (Torgan et al. 2006), a família Eunotiaceae destacou-se pela riqueza de espécies, justificando um estudo mais detalhado da morfologia e da distribuição desses organismos. Como primeiro resultado deste estudo foram apresentadas 12 novas citações para o Estado (Bicca et al. 2009).

Este trabalho tem como objetivo apresentar as características morfológicas e métricas das demais espécies de Eunotiaceae, avaliando a riqueza, a constância e a distribuição das mesmas nas áreas de estudo.

\section{Material e métodos}

O estudo baseou-se em amostragens efetuadas em 21 estações georreferenciadas, localizadas nas áreas da Lagoa do Casamento e do Butiazal de Tapes, em zonas litorâneas e pelágicas (tabela 1), entre as coordenadas $30^{\circ} 14^{\prime}-30^{\circ} 31^{\prime} \mathrm{S}$ e $50^{\circ} 33^{\prime}-51^{\circ} 23^{\prime} \mathrm{W}$ (figura 1). As coletas foram realizadas no período de outono e primavera de 2003, através da passagem de frasco na subsuperfície da água e de espremido manual das raízes e caules de macrófitas aquáticas, sendo fixadas com formaldeído e solução de Transeau na proporção de (1:100) e (1:1), respectivamente. A área da Lagoa do Casamento com 235.600 ha de extensão apresenta lagoas, banhados e canais que se interligam com a Laguna dos Patos. Esta área está mais sujeita a ação antrópica devido à orizicultura. A área do Butiazal de Tapes, com cerca de 35.667 ha apresenta lagoas, banhados e açudes fechados, isolados e mais preservados.

O material foi preparado segundo a técnica de oxidação de Van der Werff (1955), lavado e montado em lâminas, utilizando-se Naphrax ( $(R=1,74)$ como meio de inclusão. Para análise ao microscópio eletrônico de varredura (MEV), o material foi oxidado novamente com ácido nítrico $\left(\mathrm{HNO}_{3}\right)$ montado em lâminas de raio X sobre "stubs" de alumínio e metalizado com ouro. Os espécimens foram observados ao microscópio Zeiss Axioplan (aumento de 1000 a 1250 x) e ao microscópio de varredura de JEOL JSM 6060 (aumento de 650 a 25.000 x). As amostras fixadas e as lâminas permanentes encontram-se incluídas na coleção de Diatomáceas do Herbário Prof. Dr. Alarich Schultz (HAS), na Fundação Zoobotânica do Rio Grande do Sul. Temperatura, $\mathrm{pH}$ e condutividade da água foram medidos em campo utilizando-se aparelhos eletrônicos digitais marca HACH modelos 50150 e 50050. A partir dos dados de presença e ausência, foi calculado o índice

Tabela 1. Relação das estações e ambientes amostrados em zonas litorânea (L) e pelágica (P), nas áreas da Lagoa do Casamento (LC) e Butiazal de Tapes (BT), com suas coordenadas geográficas.

Table 1. Relation of the station and environments sampled at litoral (L) and pelagic (P) zones, in the Lagoa do Casamento (LC) and Butiazal de Tapes (BT) areas with their geographic coordinates.

\begin{tabular}{|c|c|c|c|c|}
\hline Estações & Áreas & Ambientes & Zonas & Coordenadas geográficas \\
\hline 1 & $\mathrm{LC}$ & Banhado entre L. Capivari e Casamento & $\mathrm{L}$ & $30^{\circ} 14^{\prime} 29^{\prime \prime}$ S e $50^{\circ} 33^{\prime} 55^{\prime \prime} \mathrm{W}$ \\
\hline 2 & $\mathrm{LC}$ & Banhado entre L. Capivari e Casamento & $\mathrm{L}$ & $30^{\circ} 14^{\prime} 32^{\prime \prime}$ S e $50^{\circ} 33^{\prime} 59^{\prime \prime} \mathrm{W}$ \\
\hline 3 & $\mathrm{LC}$ & Lagoa do Capivari & $P$ & $30^{\circ} 14^{\prime} 38^{\prime \prime}$ S e $50^{\circ} 33^{\prime} 15^{\prime \prime} \mathrm{W}$ \\
\hline 4 & $\mathrm{LC}$ & Lagoa do Casamento & $\mathrm{P}$ & $30^{\circ} 16^{\prime} 40^{\prime \prime} \mathrm{S}$ e $50^{\circ} 33^{\prime} 25^{\prime \prime} \mathrm{W}$ \\
\hline 5 & $\mathrm{LC}$ & Banhado Fazenda Rincão Anastácio & $\mathrm{L}$ & $30^{\circ} 22^{\prime} 26^{\prime \prime}$ S e $50^{\circ} 40^{\prime} 48^{\prime \prime} \mathrm{W}$ \\
\hline 6 & $\mathrm{LC}$ & Banhado Fazenda Rincão Anastácio & $\mathrm{L}$ & $30^{\circ} 22^{\prime} 26^{\prime \prime} \mathrm{S}$ e $50^{\circ} 40^{\prime} 48^{\prime \prime} \mathrm{W}$ \\
\hline 7 & $\mathrm{LC}$ & Lagoa dos Gateados Norte & $\mathrm{L}$ & $30^{\circ} 28^{\prime} 18^{\prime \prime}$ S e $50^{\circ} 40^{\prime} 4^{\prime \prime} \mathrm{W}$ \\
\hline 8 & $\mathrm{LC}$ & Lagoa dos Gateados Norte & $\mathrm{L}$ & $30^{\circ} 30^{\prime} 19^{\prime \prime} \mathrm{S}$ e $50^{\circ} 39^{\prime} 50^{\prime \prime} \mathrm{W}$ \\
\hline 9 & $\mathrm{LC}$ & Lagoa dos Gateados Norte & $\mathrm{P}$ & $30^{\circ} 30^{\prime} 26^{\prime \prime} \mathrm{S}$ e $50^{\circ} 39^{\prime} 12^{\prime \prime} \mathrm{W}$ \\
\hline 10 & $\mathrm{LC}$ & Canal do Sangradouro & $\mathrm{L}$ & $30^{\circ} 26^{\prime} 60^{\prime \prime}$ S e $50^{\circ} 39^{\prime} 29^{\prime \prime} \mathrm{W}$ \\
\hline 11 & $\mathrm{LC}$ & Lagoa dos Gateados Sul & $\mathrm{L}$ & $30^{\circ} 32^{\prime} 8^{\prime \prime}$ S e $50^{\circ} 39^{\prime} 39^{\prime \prime} \mathrm{W}$ \\
\hline 12 & $\mathrm{LC}$ & Lagoa dos Gateados Sul & $P$ & $30^{\circ} 31^{\prime} 34^{\prime \prime}$ S e $50^{\circ} 39^{\prime} 33^{\prime \prime} \mathrm{W}$ \\
\hline 13 & $\mathrm{BT}$ & Lagoa Charutão & $\mathrm{L}$ & $30^{\circ} 30^{\prime} 58^{\prime \prime}$ S e $51^{\circ} 21^{\prime} 17^{\prime \prime} \mathrm{W}$ \\
\hline 14 & BT & Lagoa Charutão & $P$ & $30^{\circ} 31^{\prime} 14^{\prime \prime} \mathrm{S}$ e $51^{\circ} 21^{\prime} 25^{\prime \prime} \mathrm{W}$ \\
\hline 15 & BT & Açude Fazenda São Miguel & $\mathrm{L}$ & $30^{\circ} 31^{\prime} 7^{\prime \prime}$ S e $51^{\circ} 22^{\prime} 23^{\prime \prime} \mathrm{W}$ \\
\hline 16 & BT & Lagoa das Capivaras & $\mathrm{L}$ & $30^{\circ} 28^{\prime} 11^{\prime \prime} \mathrm{S}$ e $51^{\circ} 16^{\prime} 30^{\prime \prime} \mathrm{W}$ \\
\hline 17 & BT & Lagoa das Capivaras & $\mathrm{P}$ & $30^{\circ} 28^{\prime} 11^{\prime \prime} \mathrm{S}$ e $51^{\circ} 16^{\prime} 30^{\prime \prime} \mathrm{W}$ \\
\hline 18 & BT & Banhado com Sphagnum & $\mathrm{L}$ & $30^{\circ} 28^{\prime} 24^{\prime \prime}$ S e $51^{\circ} 16^{\prime} 38^{\prime \prime} \mathrm{W}$ \\
\hline 19 & BT & Lagoinha entre dunas & $\mathrm{L}$ & $30^{\circ} 28^{\prime} 25^{\prime \prime}$ S e $51^{\circ} 16^{\prime} 36^{\prime \prime} \mathrm{W}$ \\
\hline 20 & BT & Banhado entre dunas & $\mathrm{L}$ & $30^{\circ} 28^{\prime} 20^{\prime \prime} \mathrm{S}$ e $51^{\circ} 16^{\prime} 30^{\prime \prime} \mathrm{W}$ \\
\hline 21 & BT & Lagoa Redonda & $\mathrm{L}$ & $30^{\circ} 31^{\prime} 36^{\prime \prime}$ S e $51^{\circ} 21^{\prime} 34^{\prime \prime} \mathrm{W}$ \\
\hline
\end{tabular}




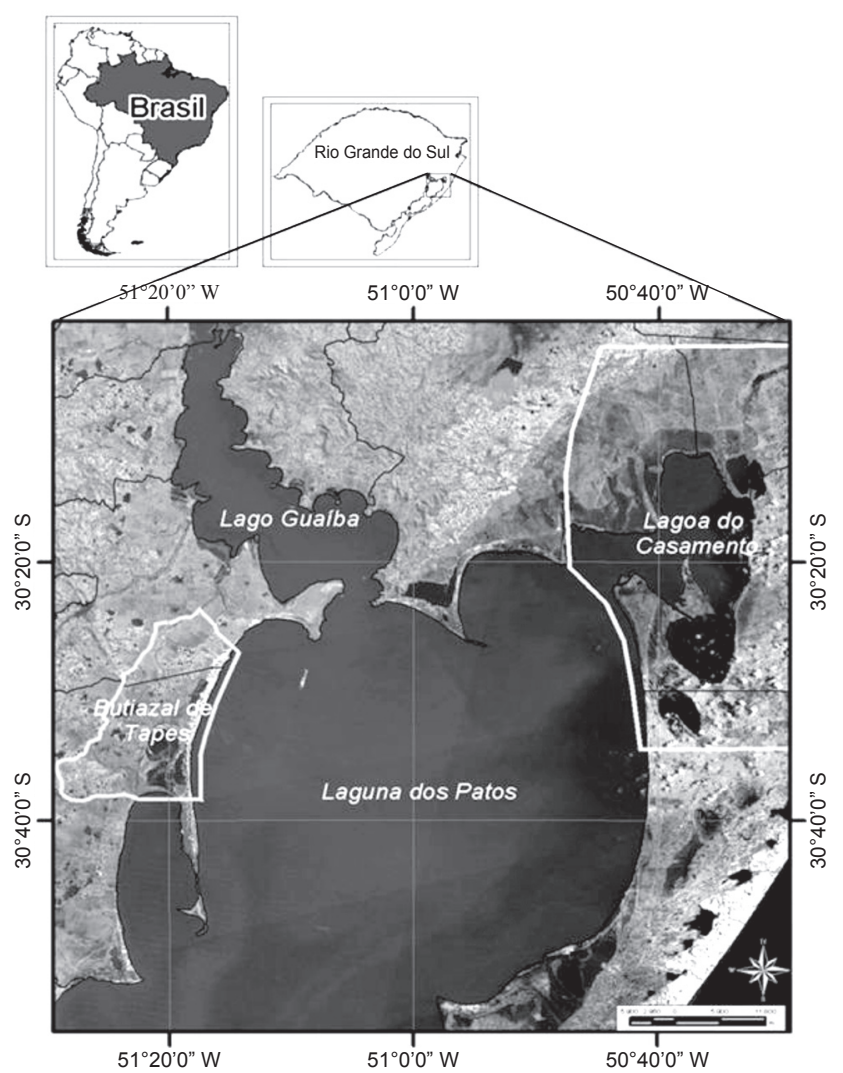

Figura 1. Localização das áreas de estudo na Planície Costeira do Rio Grande do Sul.

Figure 1. Location of the study areas in the Coastal Plain of Rio Grande do Sul. de constância das espécies, com base na distribuição dos táxons nas áreas de estudo. Considerou-se espécie constante quando a mesma ocorreu em $70 \%$ ou mais dos ambientes amostrados; espécie frequente a que esteve presente em 40 a 69\%; espécie comum aquela presente entre 20 e $39 \%$ e espécie rara a que ocorreu em menos de $20 \%$ dos ambientes nas áreas de estudo. Seguiu-se o sistema de Round et al. (1990) na classificação supragenérica. Para algumas espécies, quando necessário, foi mencionada a relação comprimento/ largura das valvas ( $\mathrm{r} \mathrm{c} / 1)$.

\section{Resultados e discussão}

Composição Taxonômica

Actinella Lewis

Actinella guianensis Grun. in Van Heurck, Syn. Diat. Belgique, Atlas, pl. 35, fig. 17, 20. 1880-1881.

Figuras 2, 3

Valvas levemente arqueadas, com margens paralelas; extremidade apical dilatada, cuneado-apiculada; extremidade basal cuneado-arredondada; espinhos proeminentes, contornando toda a valva; nódulos, quando visíveis, afastados das extremidades valvares; estrias transapicais paralelas. Medidas: 113-154 $\mu \mathrm{m}$ compr.; 6,0-8,0 $\mu \mathrm{m}$ larg.; $\mathrm{r} \mathrm{c} / 1$ 14,1-22,5; 13 estrias em $10 \mu \mathrm{m}$.

Material examinado: BRASIL. Rio GRANDE DO Sul: Tapes, lagoinha entre dunas, 04-VI-2003, L.C. Torgan \& V.R. Werner (HAS104230, lâm. 5834A e 5955); Lagoa Charutão, 02-XII-2003, L. Cardoso (HAS104425).

Chave dicotômica para identificação dos táxons de Eunotia em microscópio óptico (MO)

1. Valvas com margem dorsal ondulada 2

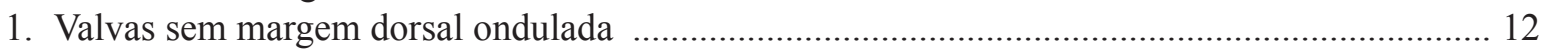

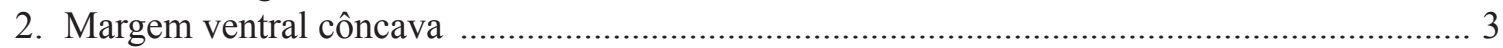

2. Margem ventral reta a levemente côncava …..................................................................... 8

3. Margem dorsal com duas ou mais ondulações ........................................................................ 4

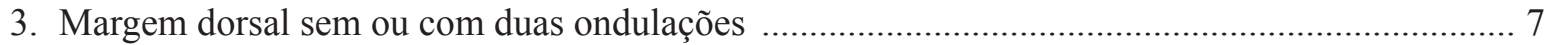

4. Margem ventral com ondulações ......................................................................... E. didyma

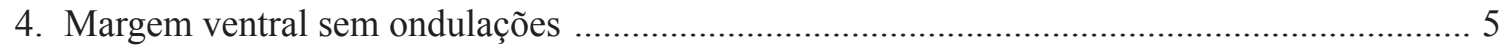

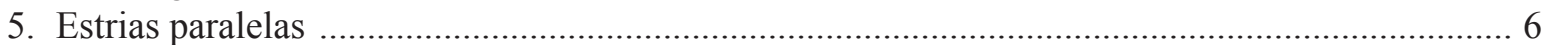

5. Estrias levemente radiadas nas extremidades ..................................................................... E. tecta

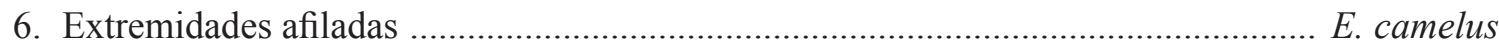

6. Extremidades não afiladas ........................................................................... E. subrobusta

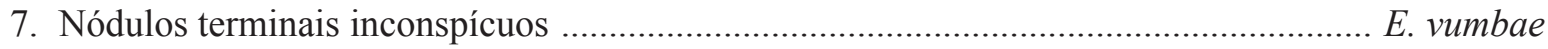

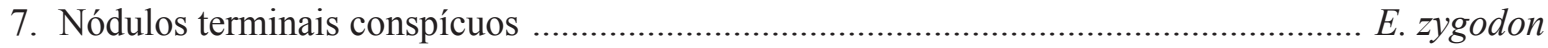

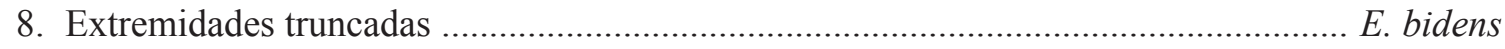

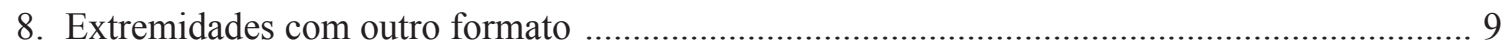

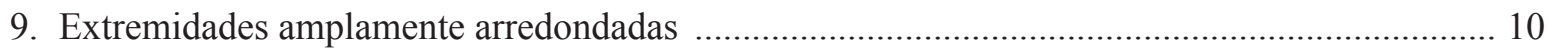

9. Extremidades não amplamente arredondadas ................................................................... 11 
10.Margem dorsal com uma ondulação E. rabenhorstii var. monodon

10.Margem dorsal com três ondulações E. rabenhorstii var. triodon

11. Margem dorsal sem ondulação E. tridentula var. monodon

11. Margem dorsal com três ondulações E. tridentula var. triodon

12.Extremidades levemente ou não destacadas do corpo valvar ............................................. 13

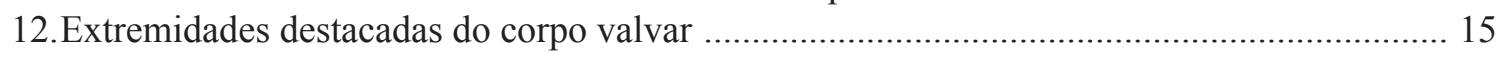

13. Rafe estendendo-se do ápice E. bilunaris

13. Rafe não se estendendo do ápice 14

14.Extremidades arredondadas E. submonodon

14.Extremidades subcapitadas E. naegelii

15.Extremidades atenuado-subagudas E. pseudosudetica

15.Extremidades com outro formato 16

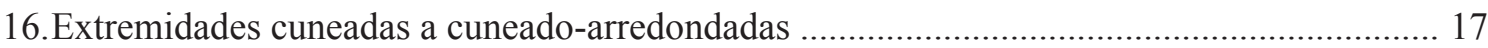

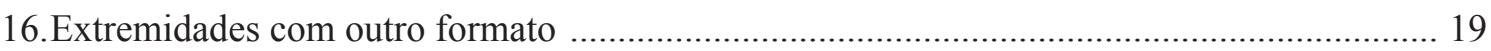

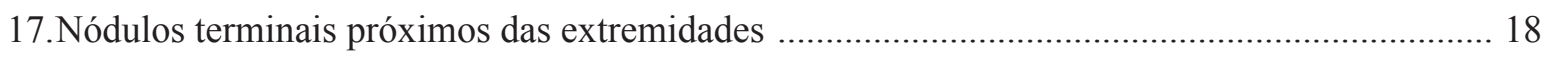

17. Nódulos terminais nas extremidades E. yberai

18. Extremidades cuneado-afiladas E. pseudoindica

18. Extremidades cuneado-arredondadas E. indica

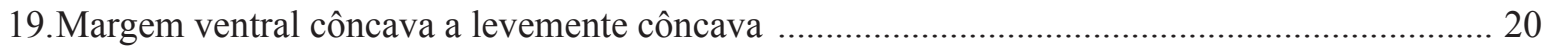

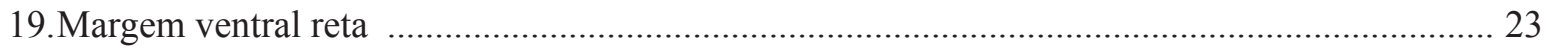

20.Extremidadades arredondadas ou truncado-arredondadas ...................................................... 21

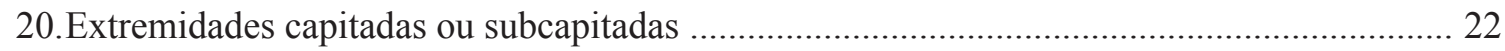

21.17-27 estrias em $10 \mu \mathrm{m}$ E. asterionelloides

21.10-12 estrias em $10 \mu \mathrm{m}$ E. maior

22.Nódulos terminais nas extremidades

E. paludosa

22. Nódulos terminais próximos das extremidades

E. pectinalis

23. Rafe estendendo-se do ápice E. flexuosa

23. Rafe não se estendendo do ápice 24

24.Extremidades atenuado-arredondadas E. itapuana

24. Extremidades subcapitadas

E. veneris

Eunotia asterionelloides Hust., Ber. dt. bot. Ges., 65: 138, figs. 18, 19. 1952.

Figuras 4, 46

Valvas com margem dorsal levemente convexa; margem ventral levemente côncava; extremidades truncado-arredondadas; nódulos terminais nas extremidades valvares pouco nítidos, delicados, às vezes inconspícuos; estrias transapicais paralelas a levemente radiadas em direção às extremidades. Em MEV observa-se uma rimopórtula presente em uma das extremidades da valva, de posição oblíqua em relação à helictoglossa. Medidas: 15-33 $\mu \mathrm{m}$ compr.; 1,8-3,2 $\mu \mathrm{m}$ larg.; r c/1 7,8-8,3; 17-27 estrias em $10 \mu \mathrm{m} ; 40-50$ aréolas em $10 \mu \mathrm{m}$.

Os indivíduos analisados diferem morfologicamente da descrição original por não apresentarem a margem dorsal reta, sendo semelhantes aos exemplares encontrados por Metzeltin \& Lange-Bertalot (1998) no rio Tapajós, Amazonas.
Material examinado: BRASIL. Rio GRANDE Do Sul: Palmares do Sul, banhado Fazenda Rincão do Anastácio, 07-V-2003, V.R. Werner (HAS104121, lâm. 5814); Tapes, Lagoa das Capivaras, 04-VI-2003, L.C. Torgan \& V.R. Werner (HAS104215, lâm. 5782); 03-XII-2003, S.M. Alves-da-Silva (HAS104435, lâm. 5846); Lagoa Redonda, 03-XII-2003, L. Cardoso (HAS104455, lâm. 5867).

Eunotia bidens Ehr., Ber. K. Akad. Wiss. Berlin, p.204. 1841.

Figuras 5, 6, 49, 50

Valvas com margem dorsal convexa, apresentando duas ondulações mais ou menos proeminentes; margem ventral levemente côncava; extremidades valvares truncadas, destacadas do corpo valvar; nódulos terminais nas extremidades; estrias transapicais paralelas na porção mediana e curvo-radiadas em direção às extremidades. Em MEV, as aréolas, em vista interna, parecem estar 

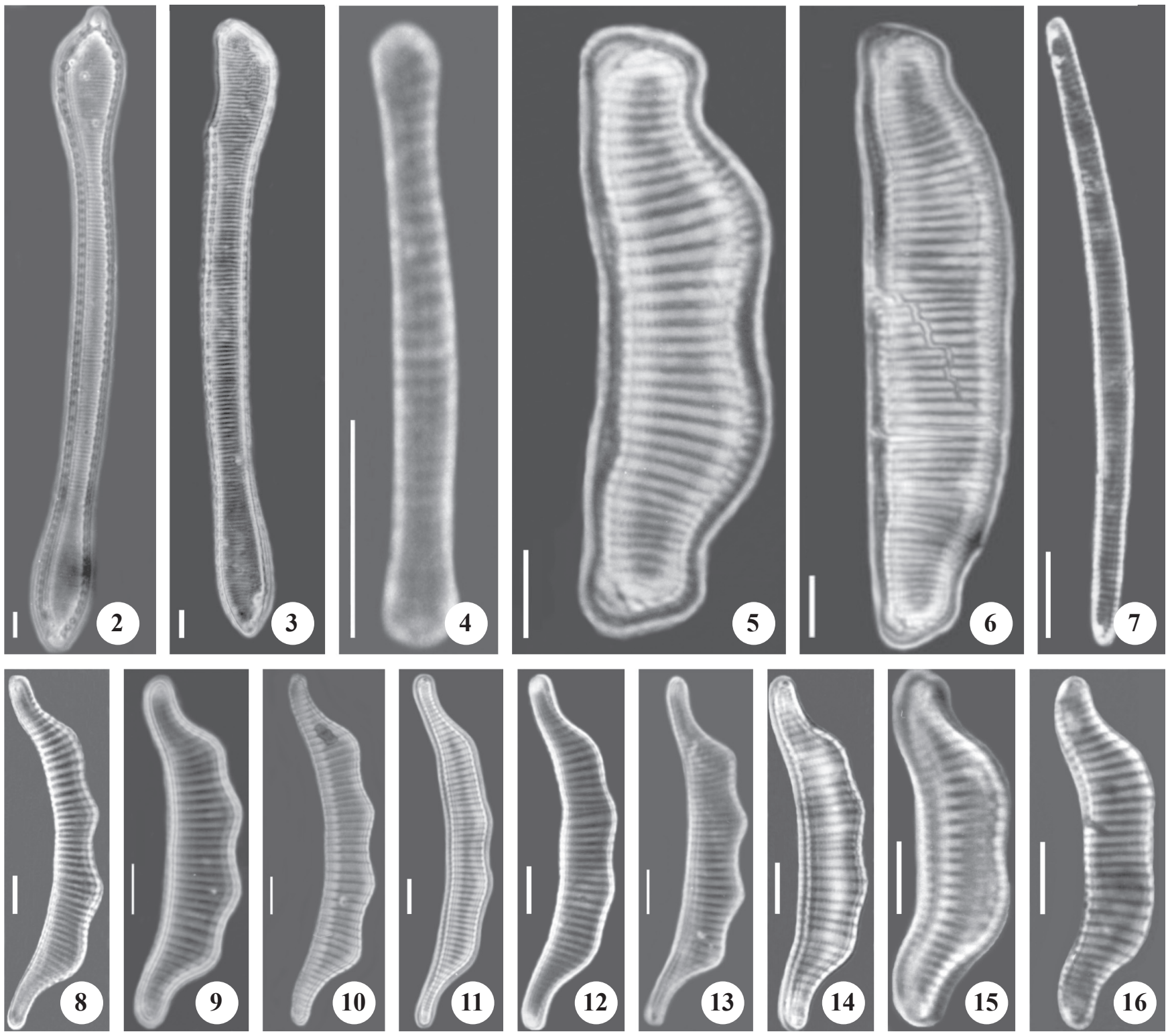

Figuras 2-16. Ilustrações em MO. 2, 3. Actinella guianensis. 4. Eunotia asterionelloides. 5, 6. E. bidens. 7. E. bilunaris. 8-16. E. camelus. Barra $=5 \mu \mathrm{m}(2,3,5,6,8-16), 10 \mu \mathrm{m}(4,7)$.

Figures 2-16. Illustrations in LM. 2, 3. Actinella guianensis. 4. Eunotia asterionelloides. 5, 6. E. bidens. 7. E. bilunaris. 8-16. E. camelus. Bar $=5 \mu \mathrm{m}(2,3,5,6,8-16), 10 \mu \mathrm{m}(4,7)$.

interligadas, formando uma linha contínua. Somente na margem dorsal elas se apresentam isoladas. Medidas: 34,2-52,8 $\mu \mathrm{m}$ compr.; 8,4-12 $\mu \mathrm{m}$; larg.; $\mathrm{r}$ c/1 3,5-4,4; estrias 9-10 em $10 \mu \mathrm{m}$; aréolas 40 em $10 \mu \mathrm{m}$.

Material examinado: BRASIL. Rio GRANDE DO Sul: Capivari do Sul, banhado entre Lagoa do Capivari e Lagoa do Casamento, 05-V-2003, V.R. Werner (HAS104096, lâm. 5811, HAS104092, lâm. 5808 e 5809); Palmares do Sul, Lagoa do Casamento, 19-XI-2003, S.M. Alves-daSilva (HAS104360, lâm. 5844); Canal do Sangradouro, 19-XI-2003, L. Cardoso (HAS104386, lâm. 5851).
Eunotia bilunaris (Ehr.) Souza, Bull. Jardin Bot. Belgique, 67: 265-266, fig. 13. 1999.

Figuras 7, 47-48

Valvas levemente arqueadas, com margem dorsal convexa; margem ventral côncava; extremidades valvares atenuado-arredondadas, não destacadas do corpo valvar; nódulos terminais nas extremidades; rafe estendendo-se do ápice para a região central da valva; estrias transapicais paralelas e equidistantes. Em MEV, a abertura da rimoportula, em vista externa, apresenta-se 
alongada, no ápice do eixo apical. A rafe é curvada, com terminação distal prolongando-se no eixo apical da superfície valvar, em direção ao centro da valva. Medidas: 50,9-147,4 $\mu \mathrm{m}$ compr.; 2,5-5,0 $\mu \mathrm{m}$ larg.; $\mathrm{rc} / 1$ 17-50; estrias 12-20 em $10 \mu \mathrm{m}$; aréolas 40 em $10 \mu \mathrm{m}$.

O material apresentou grande variação métrica, mas pouca diferenciação quanto ao formato das valvas. Em MO, no indivíduo de maior tamanho, foi possível observar o formato peculiar da rafe, característica demonstrada por Le Cohu (1993). Citada como E. curvata (Kütz.) Lagerst var. curvata no Banhado Grande por Torgan \& Delani (1988), no Parque Estadual de Itapuã por Torgan et al. (1993) e no Arroio Sampaio por Oliveira et al. (2001). Souza \& Moreira (1999) justifica o motivo pelo qual não é válida a denominação E. binularis (Ehr.) Mills para o táxon.

Material examinado: BRASIL. Rio GRANDE DO Sul: Capivari do Sul, banhado entre Lagoa do Capivari e Lagoa do Casamento, 05-V-2003, V.R. Werner (HAS104096, lâm. 5811); Palmares do Sul, Canal do Sangradouro, 19-X-2003, L. Cardoso (HAS104386), 30-X-2003, S.M. Alves-da-Silva (HAS104392, lâm. 5854); Tapes, banhado com Sphagnum, 03-XII-2003, L. Cardoso (HAS104440lâm. 5869); Lagoa Redonda, 03-XII-2003, L. Cardoso (HAS104455, lâm. 5867); Mostardas, Lagoa dos Gateados Sul, 31-X-2003, L. Cardoso (HAS104403, lâm. 5874).

Eunotia camelus Ehr., Phys. Abh. K. Akad. Wiss. Berlin (125), pl. 211, fig. 1. 1841.

Figuras 8-16

Valvas com margem dorsal convexa, apresentando de duas a quatro ondulações; margem ventral côncava, às vezes apresentando uma leve intumescência na porção mediana; extremidades valvares afiladas, arredondadas, voltadas para a margem dorsal da valva; nódulos terminais nas extremidades; estrias transapicais paralelas, com aréolas geralmente conspícuas. Medidas: 17,4-52,2 $\mu \mathrm{m}$ compr.; 4,2-7,2 $\mu \mathrm{m}$ larg.; $\mathrm{r}$ c./1 4,1-8,1; estrias 9-10 em $10 \mu \mathrm{m}$; aréolas $30 \mathrm{em} 10 \mu \mathrm{m}$.

De acordo com a forma e número de ondulações da margem dorsal, Grunow (1865) e Frenguelli (1931-1933) definiram as formas com duas ondulações como var. camelus (figuras 15 e 16) e as com quatro ondulações, como var. denticulata (figuras $8,9,10,11$ ) e var. didymodon (figuras 12, 13, 14). Posteriormente, Schmidt et al. (1874-1959) não consideraram essas variedades, demonstrando a ocorrência de formas intermediárias entre as mesmas. Outros caracteres, como a posição e o formato da rafe, mantiveram-se estáveis nas populações observadas. É importante mencionar que os diferentes morfotipos foram encontrados em um mesmo ambiente, eliminando a possibilidade das diferenças morfológicas serem uma resposta a condições ambientais distintas.

Material examinado: BRASIL. Rio GRANDE DO Sul: Capivari do Sul, banhado entre Lagoa do Capivari e Lagoa do Casamento, 05-V-2003, V.R. Werner (HAS104096, lâm. 5811, HAS104092, lâm. 5808); Tapes, Lagoa das Capivaras, 04-VI-2003, L.C. Torgan \& V.R. Werner (HAS104215, lâm. 5782); 03-XII-2003, S.M. Alves-da-Silva (HAS104435, lâm. 5846); lagoinha entre dunas, 04-VI-2003, L.C. Torgan \& V.R. Werner (HAS104230, lâm. 5834A); Palmares do Sul, Canal do Sangradouro, 19-XI-2003, L. Cardoso (HAS104386, lâm. 5851); banhado Fazenda Rincão do Anastácio, 07-V-2003, V.R. Werner (HAS104121, 104123, lâm. 5813, 5814, 5783, 5789); Mostardas, Lagoa dos Gateados Sul, 31-X-2003, S.M. Alves-da-Silva (HAS104403, lâm. 5874).

Eunotia didyma Hust. ex Zimm., Broteria, Ser, Bot. 13(2): 51, pl. 5, fig. 6, pl. 6, figs. 2, 3, 7. 1915.

Figuras 17-23, 51

Valvas com margem dorsal convexa, apresentando de duas a cinco ondulações; margem ventral côncava, com duas a cinco ondulações; às vezes apresentam uma intumescência na região central de ambas as valvas; extremidades valvares apiculadas, cuneadoapiculadas e atenuado-arredondadas; nódulos terminais nas extremidades; estrias transapicais paralelas na porção mediana e curvo-radiadas nas extremidades, interrompidas próximo à margem ventral, formando uma área longitudinal estreita e hialina; aréolas conspícuas. Em MEV observa-se uma rimoportula presente na extremidade, no eixo apical da superfície valvar, oblíqua em relação à helictoglossa. Em vista externa, a rafe estende-se em direção à margem ventral. Medidas: $37-$ $93 \mu \mathrm{m}$ compr.; 10,8-17 $\mu \mathrm{m}$ larg.; $\mathrm{r} \mathrm{c} / 1$ 3,3-6,1; estrias 8-13 em $10 \mu \mathrm{m}$; aréolas 22-25 em $10 \mu \mathrm{m}$.

Os indivíduos analisados apresentaram variação no número de ondulações e na presença ou ausência de intumescência na região central da valva. De acordo com essas características, Zimmermann (1915), baseado nas ilustrações de Hustedt in Schmidt (1972), descreveu diferentes variedades e formas, quais sejam: var. tuberosa Hust. ex Zimm., que possui uma intumescência central (figura 19), var. claviculata Hust. ex Zimm., caracterizada por possuir as extremidades mais alargadas (figura 18) e f. genuina Hust. ex Zimm., que apresenta duas 

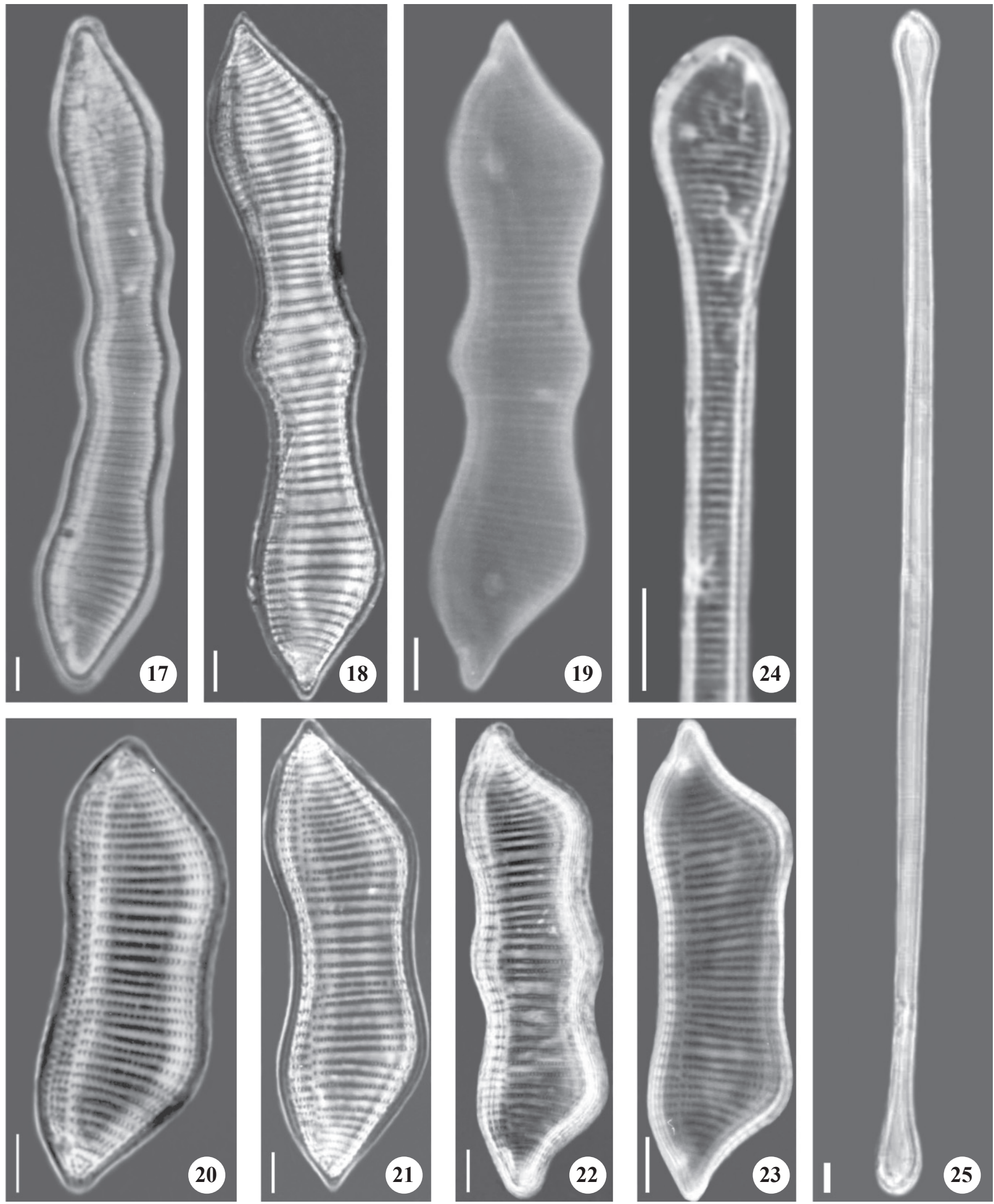

Figuras 17-25. Ilustrações em MO. 17-23. Eunotia didyma. 24, 25. E. flexuosa. Barra = $4 \mu \mathrm{m}$ (17-19, 25$), 5 \mu \mathrm{m}(20-23), 15$ $\mu \mathrm{m}(24)$.

Figures 17-25. Illustrations in LM. 17-23. Eunotia didyma. 24, 25. E. flexuosa. Bar $=4 \mu \mathrm{m}(17-19,25), 5 \mu \mathrm{m}(20-23)$, $15 \mu \mathrm{m}(24)$. 

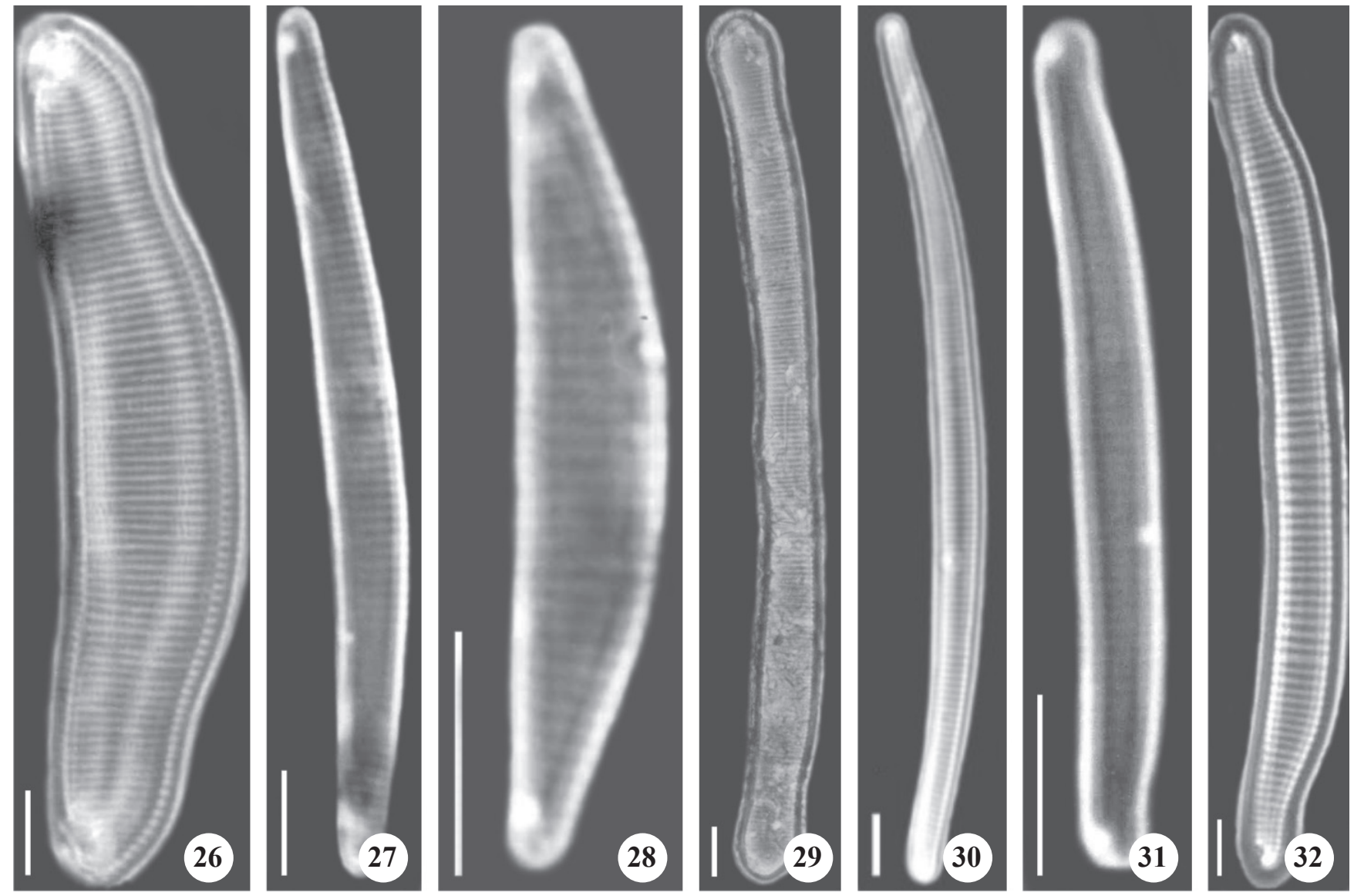

Figuras 26-32. Ilustrações em MO. 26. Eunotia indica. 27, 28. E. itapuana. 29. E. maior. 30. E. naegelii. 31. E. paludosa. 32. E. pectinalis. Barra $=8 \mu \mathrm{m}(29), 5 \mu \mathrm{m}(26,28,30,32), 4 \mu \mathrm{m}(27), 3 \mu \mathrm{m}(31)$.

Figures 26-32. Illustrations in LM. 26. Eunotia indica. 27, 28. E. itapuana. 29. E. maior. 30. E. naegelii. 31. E. paludosa. 32. E. pectinalis. $\mathrm{Bar}=8 \mu \mathrm{m}(29), 5 \mu \mathrm{m}(26,28,30,32), 4 \mu \mathrm{m}(27), 3 \mu \mathrm{m}(31)$.

ondulações na margem dorsal e extremidades cuneadoapiculadas (figura 21). Alguns espécimes (figuras 22, 23) são semelhantes aos encontrados por Torgan (1983) na represa de Águas Belas, Viamão, RS e descritos como var. pseudogibbosa Torgan. Observou-se um exemplar com quatro ondulações (figura 17), além da intumescência na região central, que se assemelha a E. elongata (Grun.) Metz. \& Lange-Bert., porém este táxon possui somente $\mathrm{o}$ intumescimento central, sem ondulações.

Com base na gradual variação morfológica das populações observadas e sua interrelação, considerase tratar de morfotipos de E. didyma, excluindo a possibilidade da ocorrência de variedades taxonômicas de acordo com Torgan \& Delani (1988) e Bicudo et al. (1995).

Material examinado: BRASIL. Rio GRANDE DO Sul: Capivari do Sul, banhado entre Lagoa do Capivari e Lagoa do Casamento, 05-V-2003, V.R. Werner (HAS104096, lâm. 5811, HAS104092, lâm. 5808 e 5809);
Mostardas, Lagoa dos Gateados Norte, 08-V-2003, V.R. Werner (HAS104141, lâm. 5737 e 5738); Palmares do Sul, Canal do Sangradouro, 19-XI-2003, L. Cardoso (HAS104386, lâm. 5851 e 5852); Lagoa do Casamento, 19-XI-2003, L. Cardoso (HAS104360, lâm. 5844); banhado Fazenda Rincão do Anastácio, 07-V-2003, V.R. Werner (HAS104121, lâm. 5814, HAS104123, lâm. 5789); Tapes, Lagoa das Capivaras, 03-XII-2003, S.M. Alves-da-Silva (HAS104435, lâm. 5846); banhado entre dunas, 04-VI-2003, L.C. Torgan \& V.R. Werner (HAS104234).

Eunotia flexuosa Bréb. ex Kütz., Sp. Alg., p.6. 1849.

Figuras 24, 25, 52

Valvas lineares, com margens paralelas; extremidades valvares dilatadas, com ápices cuneado-arredondados, destacadas do corpo valvar; nódulos terminais próximos das extremidades; rafe estendendo-se do ápice para a 


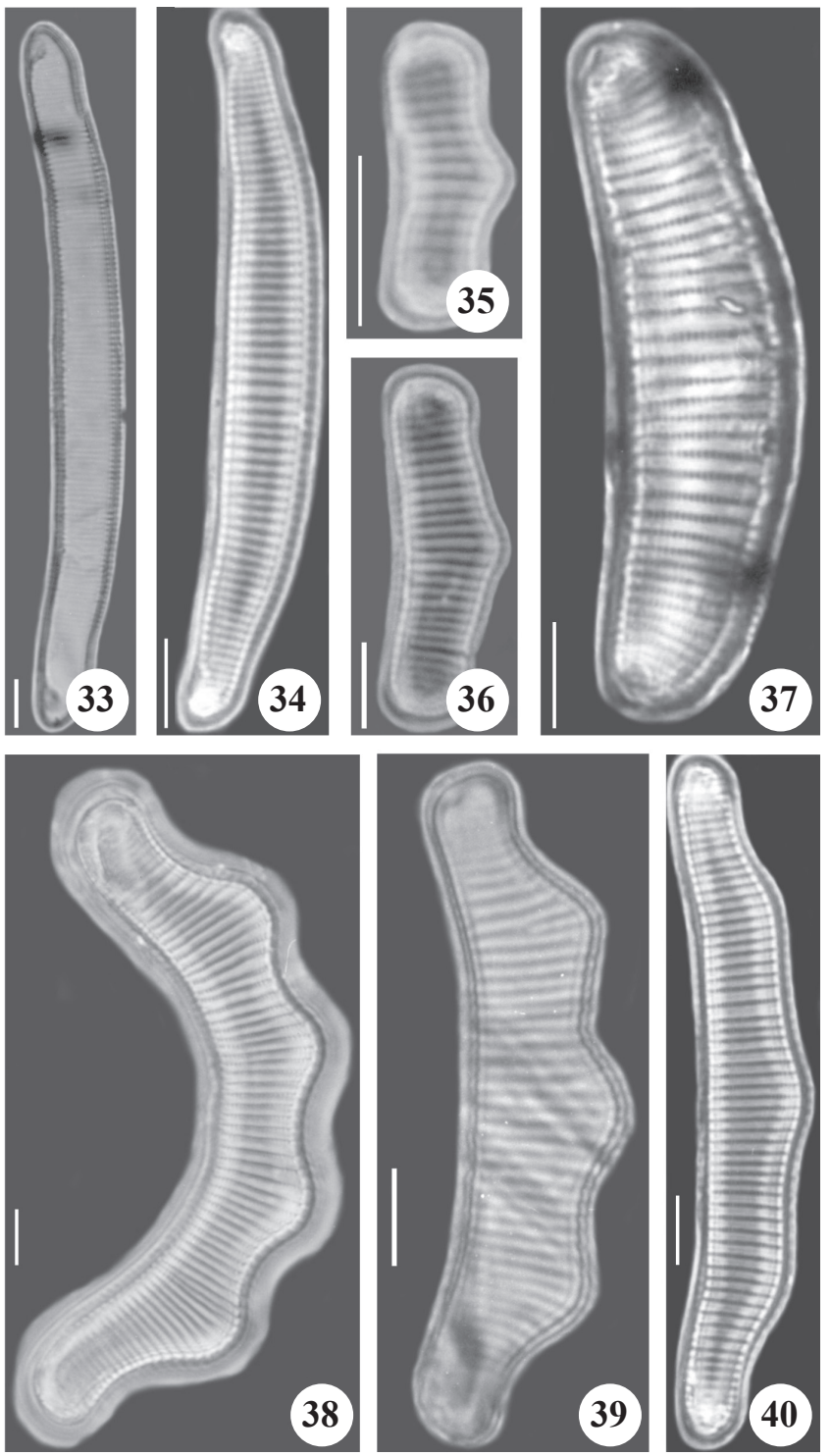

Figuras 33-40. Ilustrações em MO. 33. Eunotia pseudoindica. 34. E. pseudosudetica. 35. E. rabenhorstii var. monodon. 36. E. rabenhorstii var. triodon. 37. E. submonodon. 38. E. subrobusta. 39. E. tecta. 40. E. tridentula var. tridentula. Barra $=6 \mu \mathrm{m}(35), 5 \mu \mathrm{m}(33,34,36,37,39,40), 4 \mu \mathrm{m}(38)$.

Figures 33-40. Illustrations in LM. 33. Eunotia pseudoindica. 34. E. pseudosudetica. 35. E. rabenhorstii var. monodon. 36. E. rabenhorstii var. triodon. 37. E. submonodon. 38. E. subrobusta. 39. E. tecta. 40. E. tridentula var. tridentula. Bar $=6 \mu \mathrm{m}(35), 5 \mu \mathrm{m}(33,34,36,37,39,40), 4 \mu \mathrm{m}(38)$.

superfície da valva; estrias transapicais equidistantes, paralelas a levemente radiadas nas extremidades, com aréolas geralmente conspícuas. Em MEV observa-se a presença de uma rimoportula por valva que, em vista externa, possui a abertura alongada, localizada no ápice do eixo apical. A rafe é curvada, com terminação distal prolongando-se na superfície valvar em direção ao centro da valva. Medidas: 96-184 $\mu \mathrm{m}$ compr.; 3-6 $\mu \mathrm{m}$ larg.; $\mathrm{r}$ c/1 19,2-61,3; estrias 15-22 em $10 \mu \mathrm{m}$; aréolas 40 em $10 \mu \mathrm{m}$.

O material analisado apresentou pouca variação morfológica. Este táxon, contudo, pode demonstrar variação em relação ao formato das extremidades, desde muito dilatadas, arredondadas e destacadas do corpo valvar até arredondadas e não se destacando do corpo valvar, como apresentado por Hustedt in Schmidt et al. (1874-1959).

Material examinado: BRASIL. Rio GRANDE DO Sul: Capivari do Sul, banhado entre Lagoa do Capivari e Lagoa do Casamento, 05-V-2003, V.R. Werner (HAS104096, lâm. 5811, HAS104092, lâm. 5808 e 5809), 27-X-2003, S.M. Alves-da-Silva (HAS104342, lâm. 5772); Lagoa do Capivari, 05-V-2003, L.C. Torgan (HAS104101, lâm. 5764); Tapes, lagoinha entre dunas, 04-VI-2003, L.C. Torgan \& V.R. Werner (HAS104230, lâm. 5834A e 5955); banhado entre dunas, 04-VI-2003, L.C. Torgan \& V.R. Werner (HAS104234, lâm. 5815 e 5818); 03-XII-2003, L. Cardoso (HAS104449); Lagoa Redonda, 03-XII-2003, L. Cardoso (HAS104455, lâm. 5867); Palmares do Sul, banhado Fazenda Rincão do Anastácio, 07-V-2003, V.R. Werner (HAS104121, lâm. 5813 e 5814, HAS104123, lâm. 5789); Lagoa dos Gateados Norte, 28-X-2003, S.M. Alves-da-Silva (HAS104365, lâm. 5776), 08-V-2003, V.R. Werner (HAS104140, lâm. 5737 e 5738); Lagoa do Casamento, 19-XI-2003, L. Cardoso (HAS104360, lâm. 5844); Canal do Sangradouro, 19-XI-2003, L. Cardoso (HAS104386, lâm. 5851 e 5852), 30-X-2003, S.M. Alves-da-Silva (HAS104392, lâm. 5854); Mostardas, Lagoa dos Gateados Sul, 31-X-2003, S.M. Alves-daSilva (HAS104403, lâm. 5874).

Eunotia indica Grun., in Rab., Beitr. Nähr. Kenntn. Verbr. Alg., 2 (5), pl. 1, fig. 7. 1865.

Figuras 26, 53

Valvas com margem dorsal convexa; margem ventral levemente côncava; extremidades valvares cuneadoarredondadas, destacadas do corpo valvar; nódulos terminais próximos das extremidades; estrias transapicais paralelas a radiadas em direção às extremidades. Em $\mathrm{MEV}$, apresenta uma rimoportula diminuta, presente em uma das extremidades da valva, de posição oblíqua em relação à helictoglossa. Em vista externa, a rafe apresenta formato sigmóide, prolongando-se até o eixo apical. Presença de um espinho obtuso no ápice de cada extremidade. Medidas: 32,5-75,8 $\mu \mathrm{m}$ compr.; 

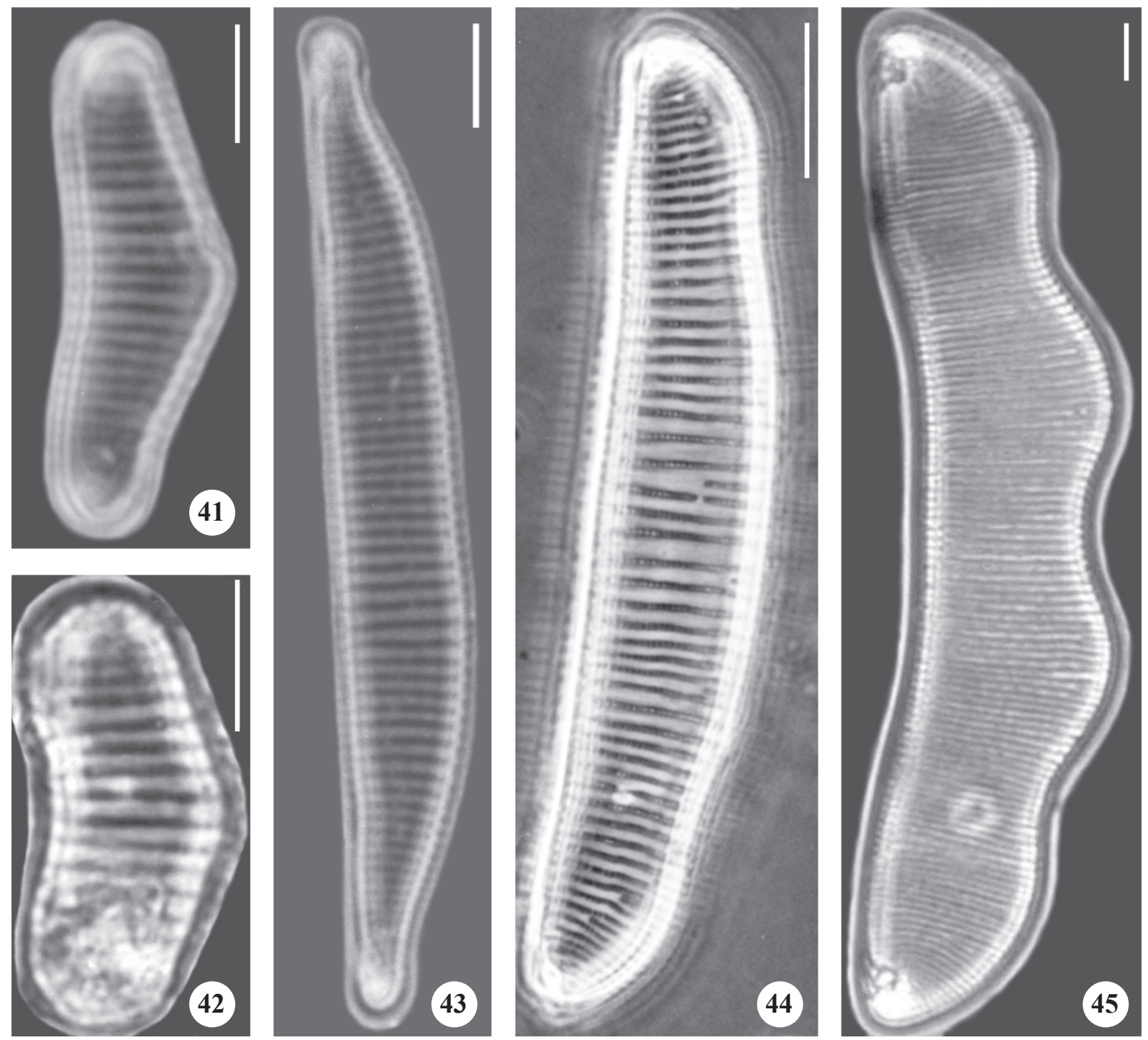

Figuras 41-45. Ilustrações em MO. 41. Eunotia tridentula var. monodon. 42. E. vumbae. 43. E. veneris. 44. E. yberai. 45. E. zygodon. Barra $=10 \mu \mathrm{m}(44), 5 \mu \mathrm{m}(41,42,45), 4 \mu \mathrm{m}(43)$.

Figures 41-45. Illustrations in LM. 41. Eunotia tridentula var. monodon. 42. E. vumbae. 43. E. veneris. 44. E. yberai. 45. E. zygodon. $\mathrm{Bar}=10 \mu \mathrm{m}(44), 5 \mu \mathrm{m}(41,42,45), 4 \mu \mathrm{m}$ (43).

8,0-13,0 $\mu \mathrm{m}$ larg.; $\mathrm{rc} / 1$ 4,0-6,0; estrias 13-20 em $10 \mu \mathrm{m}$; aréolas 25-40 em $10 \mu \mathrm{m}$.

Material examinado: BRASIL. Rio GRANDE DO Sul: Tapes, banhado com Sphagnum, 03-XII-2003, L. Cardoso (HAS104440, lâm. 5869); Lagoa das Capivaras, 03-XII-2003, S.M. Alves-da-Silva (HAS104435).

Eunotia itapuana Torgan, Diatom Res., 12 (1):115, figs. 2-22. 1997.

Figuras 27, 28, 54, 55

Valvas com margem dorsal convexa; margem ventral reta a levemente côncava; extremidades valvares atenuado-arredondadas, destacadas do corpo valvar; nódulos terminais distantes das extremidades; estrias transapicais paralelas, um pouco mais concentradas nas extremidades. Em MEV, observa-se uma rimoportula em cada extremidade da valva, de posição oblíqua em relação à helictoglossa, no eixo apical ou próximo à margem ventral da valva. Medidas: $16,8-40,8 \mu \mathrm{m}$ compr.; 3,0-3,9 $\mu \mathrm{m}$ larg.; $\mathrm{r}$ c/l: 4,6-13,6; estrias 16-24 em $10 \mu \mathrm{m}$ (centro) e 24-26 em $10 \mu \mathrm{m}$ (extremidades); aréolas 25-40 em $10 \mu \mathrm{m}$.

Material examinado: BRASIL. Rio GRANDE Do Sul: Capivari do Sul, banhado entre Lagoa do Capivari e Lagoa do Casamento, 27-X-2003, S.M. 
Alves-da-Silva (HAS104341, lâm. 5771); 27-X-2003, L. Cardoso (HAS104342, lâm. 5772); Tapes, banhado com Sphagnum, 04-VI-2003, L.C. Torgan \& V.R. Werner (HAS104221, lâm. 5831 e 5832), 03-XII2003, L. Cardoso (HAS104440, lâm. 5869); Lagoa Charutão, 02-XII-2003, L. Cardoso (HAS104425, lâm. 5871); Lagoa Redonda, 03-XII-2003, L. Cardoso (HAS104455); Mostardas, Lagoa dos Gateados Sul, 31-X-2003, L. Cardoso (HAS104403, lâm. 5874); Canal do Sangradouro, 30-X-2003, S.M. Alves-da-Silva (HAS104392, lâm. 5854).

Eunotia maior (Wm. Sm.) Rab., Fl. Eur. Alg. dulcis et submarine, sect 1, p.72. 1864.

Figura 29

Valvas com margem dorsal reta a levemente convexa; margem ventral levemente côncava, podendo apresentar um leve intumescimento central; extremidades valvares arredondadas, destacadas do corpo valvar; nódulos terminais nas extremidades; estrias transapicais paralelas
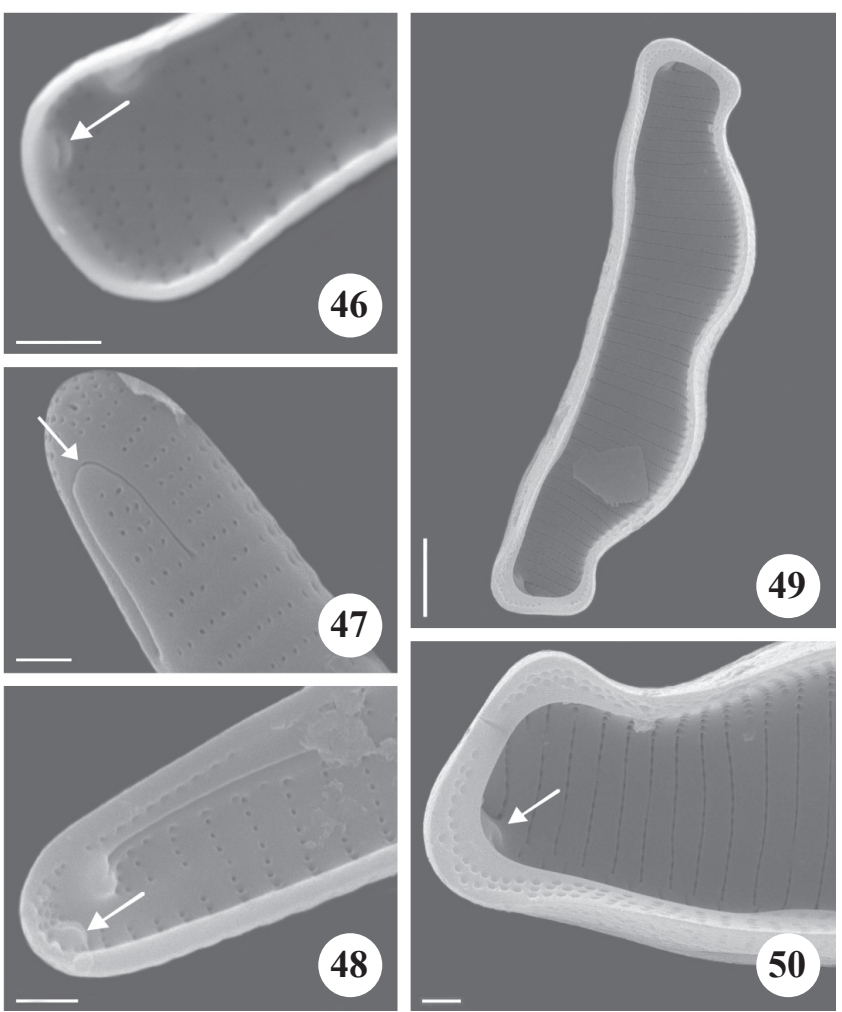

Figuras 46-50. Ilustrações em MEV. 46. E. asterionelloides. Extremidade interna mostrando a rimoportula (seta). 47, 48. E. bilunaris. 47. Extremidade externa mostrando a rafe (seta). 48. Extremidade interna mostrando a rimoportula (seta). 49, 50. E. bidens. 49. Vista valvar interna. 50. Extremidade interna mostrando a rimoportula (seta). Barra $=1 \mu \mathrm{m}(46$, $47,48,50), 5 \mu \mathrm{m}(49)$. a levemente radiadas em direção às extremidades. Medidas: 133-169 $\mu \mathrm{m}$ compr.; 10,8-11 $\mu \mathrm{m}$ larg.; $\mathrm{r} \mathrm{c} / 1$ 12,0-15,6; estrias 10-12 em $10 \mu \mathrm{m}$.

Material examinado: BRASIL. Rio GRANDE Do Sul: Capivari do Sul, banhado entre Lagoa do Capivari e Lagoa do Casamento, 05-V-2003, V.R. Werner (HAS104096, lâm. 5811, HAS104092, lâm. 5809); Lagoa do Casamento, 19-XI-2003, L. Cardoso (HAS104360, lâm. 5844).

Eunotia naegelii Mig., in Thomé, Fl. von Deutsch., v. 2, n. 1, p. 203. 1907.

Figuras 30, 56

Valvas com margem dorsal convexa; margem ventral levemente côncava; extremidades valvares dorsalmente subcapitadas, levemente destacadas do corpo valvar; nódulos terminais nas extremidades; estrias transapicais paralelas e equidistantes. Em MEV observa-se uma rimoportula presente na extremidade, de posição oblíqua em relação à helictoglossa. Medidas: 66,4-89,0 $\mu \mathrm{m}$ compr.; 3,2-5,0 $\mu \mathrm{m}$ larg.; $\mathrm{r}$ c/1 17,8-20,7; estrias $12-20$ em $10 \mu \mathrm{m}$.

Há sobreposição de medidas em relação à Eunotia genuflexa Nörpel-Sch., mas esta última se diferencia por possuir maior relação comprimento/largura e extremidades valvares arredondadas.

Material examinado: BRASIL. Rio GRANDE Do SuL: Tapes, Lagoa das Capivaras, 03-XII-2003, S.M. Alvesda-Silva (HAS104435, lâm. 5846); Lagoa dos Gateados Norte, 28-X-2003, S.M. Alves-da-Silva (HAS104365, lâm. 5776); Canal do Sangradouro, 19-XI-2003, L. Cardoso (HAS104386).

Eunotia paludosa Grun., Verh. Zool. - bot. Ges., (12): 315-472, 545-588, pl. 7. 1862.

Figuras 31, 57, 58

Valvas com margem dorsal levemente convexa; margem ventral levemente côncava; extremidades valvares dorsalmente capitadas, destacadas do corpo valvar, voltadas para a margem dorsal; nódulos terminais nas extremidades; estrias transapicais paralelas. Em

Figures 46-50. Illustrations in SEM. 46. E. asterionelloides. Internal pole showing the rimoportula (arrow). 47, 48. E. bilunaris. 47. External pole showing the raphe (arrow). 48. Internal pole showing the rimoportula (arrow). 49, 50. E. bidens. 49. Valve internal view. 50. Internal pole showing the rimoportula (arrow). Bar $=1 \mu \mathrm{m}(46,47,48,50)$, $5 \mu \mathrm{m}(49)$. 

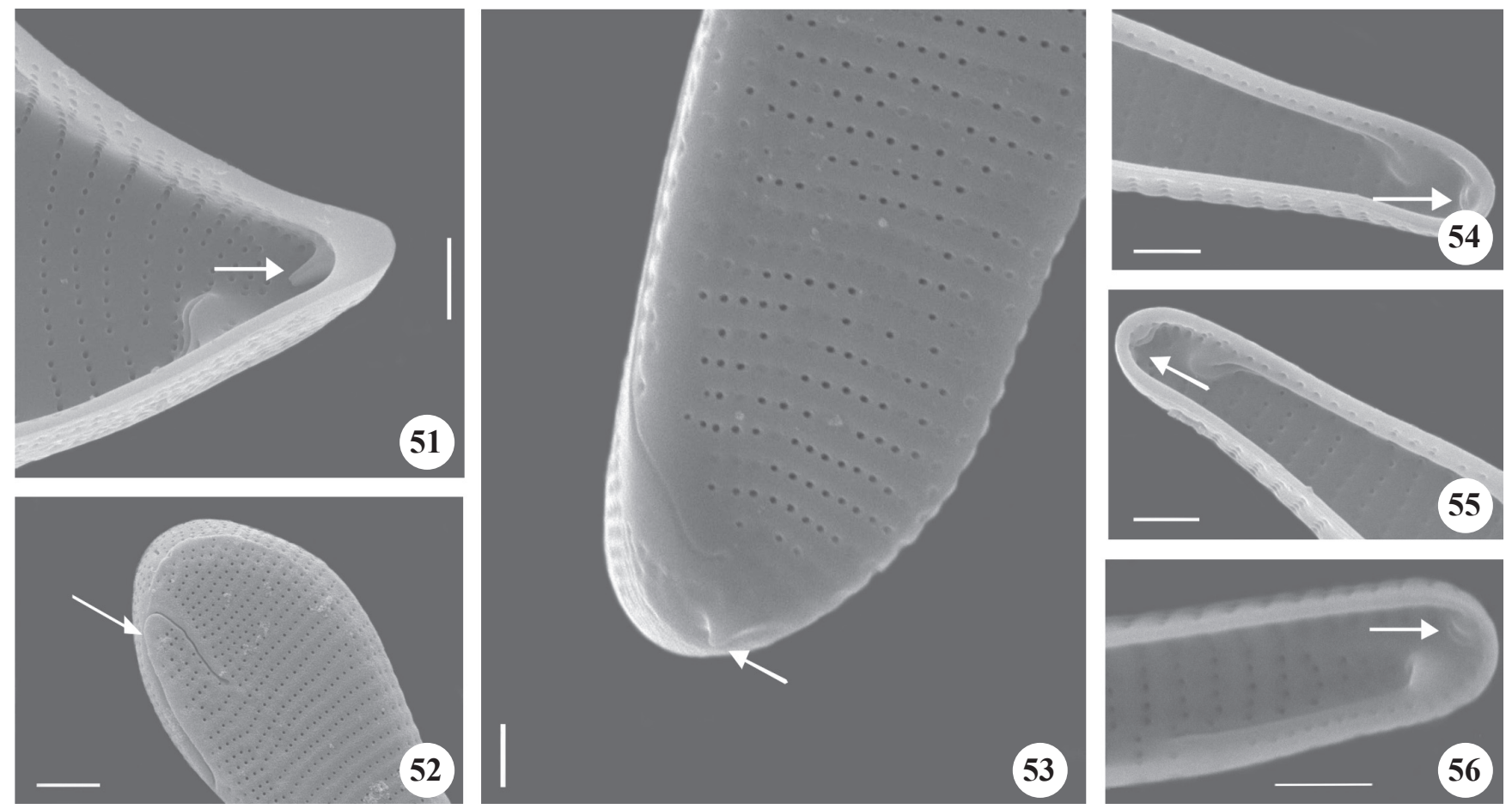

Figuras 51-56. Ilustrações em MEV. 51. Eunotia didyma. Detalhe da extremidade interna mostrando a rimoportula (seta). 52. E. flexuosa. Detalhe da extremidade externa mostrando a rafe (seta). 53. E. indica. Detalhe da extremidade externa mostrando o espinho (seta). 54, 55. E. itapuana. Detalhe das extremidades internas mostrando a rimoportula (seta). 56. E. naegelii. Detalhe da extremidade interna mostrando a rimoportula (seta). Barra $=1 \mu \mathrm{m}$ (54-56), $2 \mu \mathrm{m}$ (51-53).

Figures 51-56. Illustrations in SEM. 51. Eunotia didyma. Internal detail of the pole showing the rimoportula (arrow). 52. E. flexuosa. External detail of the pole showing the raphe (arrow). 53. E. indica. External detail of the pole showing the thorn (arrow). 54, 55. E. itapuana. Internal detail of the poles showing the rimoportulae (arrow). 56. E. naegelii. Internal detail of the pole showing the rimoportula (arrow). Bar $=1 \mu \mathrm{m}$ (54-56), $2 \mu \mathrm{m}$ (51-53).

MEV observa-se uma rimoportula presente em uma das extremidades da valva, localizada no eixo apical, de posição oblíqua em relação à helictoglossa. Possui dois espessamentos de sílica na margem ventral da valva. Medidas: 23,4 $\mu \mathrm{m}$ compr.; 2,4 $\mu \mathrm{m}$ larg.; $\mathrm{r}$ c/1 9,7; estrias 20 em $10 \mu \mathrm{m}$; aréolas 30-40 em $10 \mu \mathrm{m}$.

Material examinado: BRASIL. RIo GRANDE DO Sul: Capivari do Sul, banhado entre Lagoa do Capivari e Lagoa do Casamento, 27-X-2003, S.M. Alves-da-Silva (HAS104341); banhado com Sphagnum, 03-XII-2003, L. Cardoso (HAS104440, lâm. 5869).

Eunotia pectinalis (Kütz.) Rab., Fl. Eur. Alg. dulcis et submarine 1: 73. 1864.

Figura 32

Valvas com margem dorsal levemente convexa; margem ventral levemente côncava, apresentando ou não intumescimento na região mediana; extremidades valvares dorsalmente capitadas, destacadas do corpo valvar; nódulos terminais próximos das extremidades; estrias transapicais paralelas. Medidas: 51,2-82,5 $\mu \mathrm{m}$ compr.; 6-7,8 $\mu \mathrm{m}$ larg.; r c/1 8,8-13,3; estrias 8-13 em $10 \mu \mathrm{m}$; aréolas $30 \mathrm{em} 10 \mu \mathrm{m}$.

Material examinado: BRASIL. Rio Grande Do Sul: Capivari do Sul, banhado entre Lagoa do Capivari e Lagoa do Casamento, 05-V-2003, V.R. Werner (HAS104092, lâm. 5808 e 5809); Palmares do Sul, Canal do Sangradouro, 19-XI-2003, S.M. Alvesda-Silva (HAS104386, lâm. 5851 e 5852); banhado Fazenda Rincão do Anastácio, 07-V-2003, V.R. Werner (HAS104121, lâm. 5814); Tapes, banhado com Sphagnum, 04-VI-2003, V.R. Werner (HAS104221, lâm. 5831); lagoinha entre dunas, 04-VI-2003, L.C. Torgan \& V.R. Werner (HAS104230, lâm. 5834A); banhado entre dunas, 04-VI-2003, L.C. Torgan \& V.R. Werner (HAS104234, lâm. 5815); açude Fazenda São Miguel, 02-XII-2003, L. Cardoso (HAS104431, lâm. 5841). 

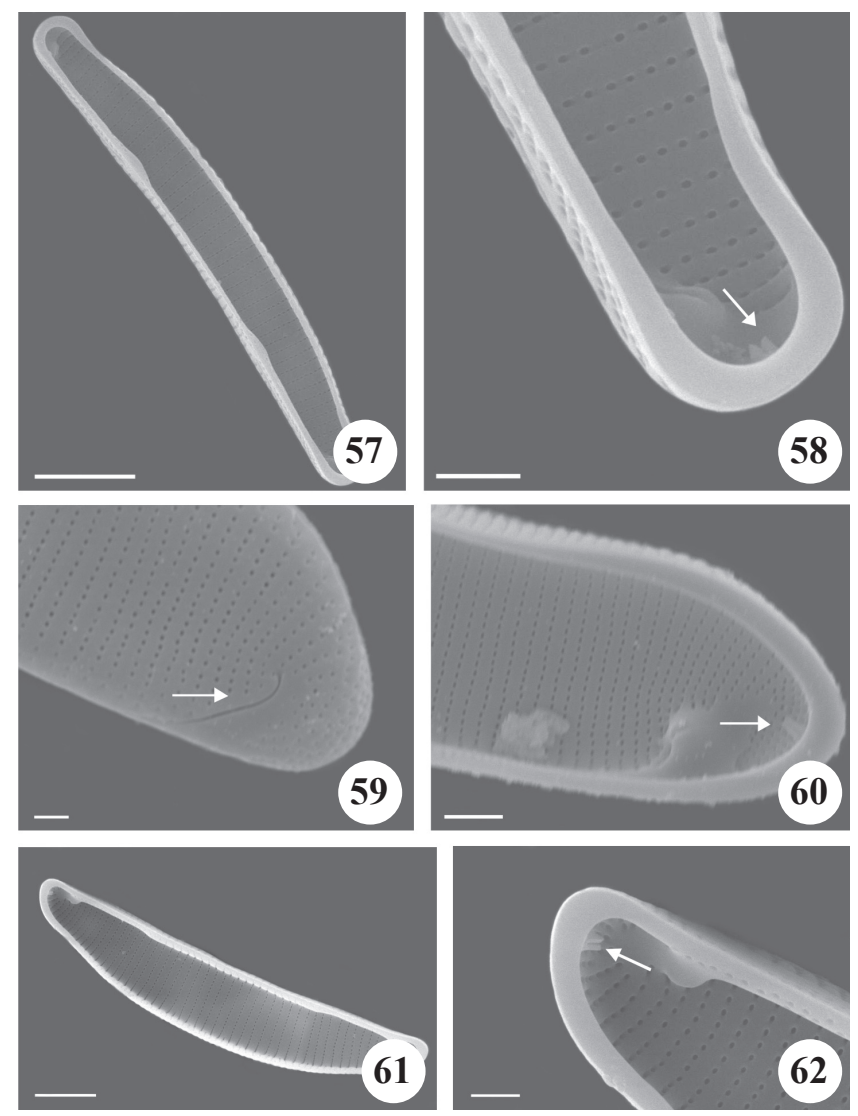

Figuras 57-62. Ilustrações em MEV. 57, 58. Eunotia paludosa. 57. Vista valvar interna. 58. Detalhe da extremidade interna mostrando a rimoportula (seta). 59, 60. E. pseudoindica. 59. Detalhe da extremidade externa mostrando a rafe (seta). 60. Detalhe da extremidade interna mostrando a rimoportula (seta). 61, 62. E. pseudosudetica. 61. Vista valvar interna. 62. Detalhe da extremidade interna mostrando a rimoportula (seta). Barra $=5 \mu \mathrm{m}(57,61), 1 \mu \mathrm{m}(58-60,62)$.

Figures 57-62. Illustrations in SEM. 57, 58. Eunotia paludosa. 57. Internal view of the valve. 58. Internal detail of the pole showing the rimoportula (arrow). 59, 60. E. pseudoindica. 59. External detail of the pole showing the raphe (arrow). 60. Internal detail of the pole showing the rimoportula (arrow). 61, 62. E. pseudosudetica. 61. Internal view of the valve. 62 . Internal detail of the pole showing the rimoportula (arrow). $\operatorname{Bar}=5 \mu \mathrm{m}(57,61), 1 \mu \mathrm{m}(58-60,62)$.

Eunotia pseudoindica Freng., Revta. Mus. La Plata, 3: 307. 1941.

Figuras 33, 59, 60

Valvas com margem dorsal levemente convexa; margem ventral levemente côncava; extremidades valvares cuneado-afiladas, destacadas do corpo valvar; nódulos terminais próximos das extremidades; estrias transapicais paralelas a radiadas em direção às extremidades. Em MEV, observa-se uma rimoportula presente em uma das extremidades da valva, de posição oblíqua em relação à helictoglossa. Em vista externa, a rafe é curvada em direção ao eixo apical. Medidas: 82-125 $\mu \mathrm{m}$ compr.; 8,1-11,4 $\mu \mathrm{m}$ larg.; $\mathrm{r}$ c/1 10,0-13,7; estrias 10-16 em $10 \mu \mathrm{m}$; aréolas 30-35 em $10 \mu \mathrm{m}$.

Os exemplares conferem com as características morfológicas e métricas da espécie apresentada por Frenguelli (1941). Este táxon foi citado como E. indica Grun. var. indica por Callegaro (1995) em turfeiras de Águas Claras.

Material examinado: BRASIL. Rio GRANDE Do Sul: Tapes, banhado com Sphagnum, 04-VI-2003, L.C. Torgan \& V.R. Werner (HAS104221, lâm. 5831 e 5832); 03-XII-2003, L. Cardoso (HAS104440, lâm. 5869); Lagoa das Capivaras, 03-XII-2003, S.M. Alves-da-Silva (HAS104435).

Eunotia pseudosudetica Metz., Lange-Bert. \& GarcíaRodr., Iconogr. Diatomol. 15: 57, pl. 24, figs. 15-18. 2005. Figuras 34, 61, 62

Valvas com margem dorsal convexa; margem ventral reta; extremidades valvares atenuado-subagudas, destacadas do corpo valvar e voltadas para a margem ventral; nódulos terminais próximos das extremidades; estrias transapicais paralelas a levemente radiadas, mais concentradas nas extremidades. Em MEV, observa-se uma rimoportula presente em uma das extremidades da valva, de posição oblíqua em relação à helictoglossa. Medidas: 41,4-42 $\mu \mathrm{m}$ compr.; 5,4-6,0 $\mu \mathrm{m}$ larg.; $\mathrm{r}$ c/1 6,6-7,0; estrias $13 \mathrm{em} 10 \mu \mathrm{m}$ (no centro) e 16-20 em $10 \mu \mathrm{m}$ (nas extremidades); aréolas $40 \mathrm{em} 10 \mu \mathrm{m}$.

Exceto pelo valores pouco inferiores da largura (o tipo possui 6,3-7,3 $\mu \mathrm{m}$ ) os exemplares analisados conferem com a circunscrição da espécie. Exemplares similares em relação à largura foram encontrados no Lago Guaíba (Torgan et al. 2009).

Material examinado: BRASIL. Rio GRANDE Do Sul: Capivari do Sul, banhado entre Lagoa do Capivari e Lagoa do Casamento, 27-X-2003, S.M. Alves-da-Silva (HAS104341); 27-X-2003, S.M. Alvesda-Silva (HAS104342, lâm. 5772); Palmares do Sul, Canal do Sangradouro, 30-X-2003, S.M. Alves-da-Silva (HAS104392, lâm. 5854).

Eunotia rabenhorstii var. monodon Cleve \& Grun., in Van Heurck, Syn. Diat. Belgique, pl. 35, fig. 12B. 1880-1881.

Figura 35

Valvas com margem dorsal convexa, apresentando uma ondulação; margem ventral levemente côncava; extremidades valvares arredondadas, amplamente 


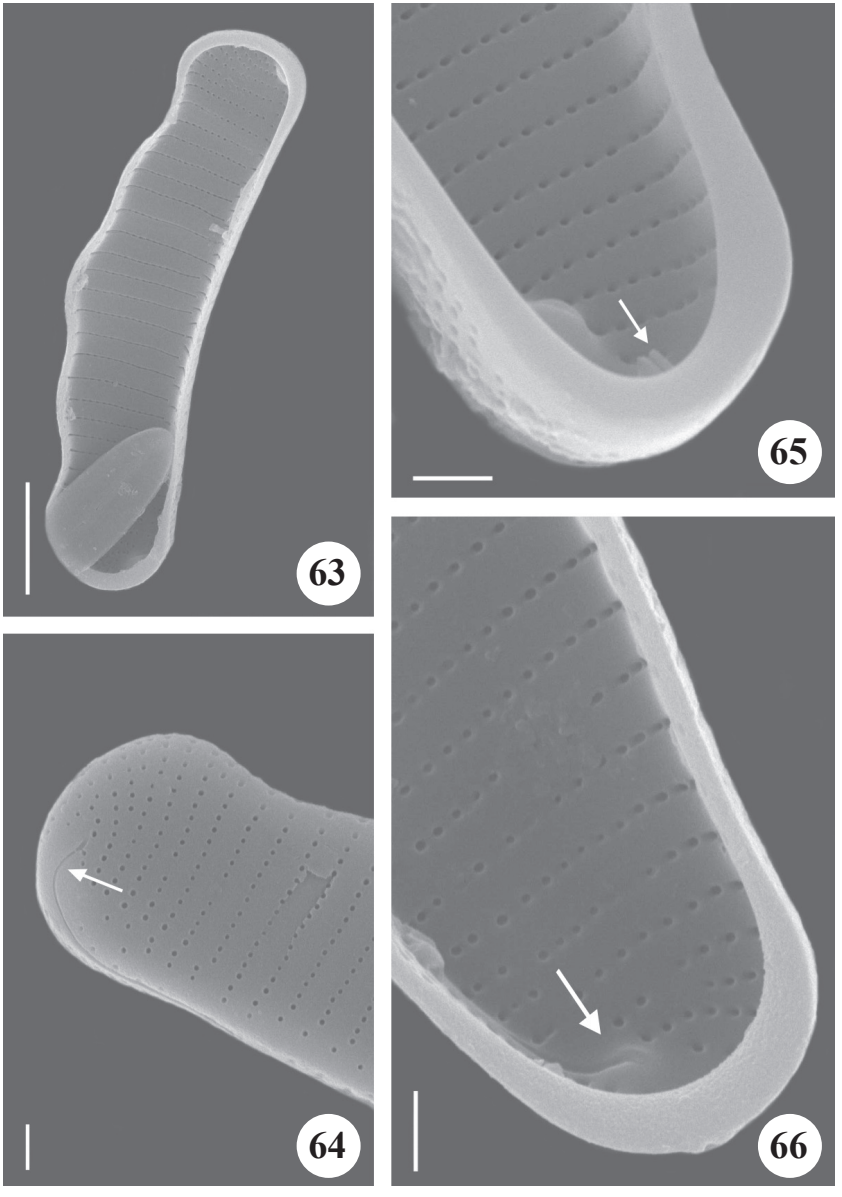

Figuras 63-66. Ilustrações em MEV. 63, 64. Eunotia rabenhorstii var. triodon. 63. Vista valvar interna. 64. Extremidade externa mostrando a rafe (seta). 65. E. tridentula var. tridentula. Detalhe da extremidade interna mostrando a rimoportula (seta). 66. E. tridentula var. monodon. Detalhe da extremidade interna mostrando a helictoglossa (seta). Barra $=5 \mu \mathrm{m}$ (63), $1 \mu \mathrm{m}$ (64-66).

Figures 63-66. Illustrations in SEM. 63, 64. Eunotia rabenhorstii var. triodon. 63. Internal view of the valve. 64 . External pole showing the raphe arrow. 65. E. tridentula var. tridentula. Internal detail of the pole showing the rimoportula (arrow). 66. E. tridentula var. monodon. Internal detail of the pole showing the helictoglossa (arrow). Bar $=5 \mu \mathrm{m}$ (63), 1 $\mu \mathrm{m}$ (64-66).

dilatadas, destacadas do corpo valvar; nódulos terminais pouco nítidos nas extremidades, quase imperceptíveis; estrias transapicais paralelas a levemente radiadas em direção às extremidades. Medidas: 10,8 $\mu \mathrm{m}$ compr.; $4,8 \mu \mathrm{m}$ larg.; $\mathrm{r}$ c/1 2,2; estrias 10 em $10 \mu \mathrm{m}$; aréolas 30 em $10 \mu \mathrm{m}$.

Material examinado: BRASIL. Rio GRANDE Do SuL: Capivari do Sul, banhado entre Lagoa do Capivari e Lagoa do Casamento, 27-X-2003, S.M. Alves-da-Silva
(HAS104341); Palmares do Sul, Lagoa do Casamento, 19-XI-2003, L. Cardoso (HAS104360, lâm. 5844); Tapes, Lagoa das Capivaras, 03-XII-2003, S.M. Alvesda-Silva (HAS104435).

Eunotia rabenhorstii var. triodon Cleve \& Grun., in Van Heurck, Syn. Diat. Belgique, pl. 35, fig. 12A. 1880-1881. Figuras 36, 63, 64

Valvas com margem dorsal convexa, apresentando três ondulações, sendo a da região mediana mais pronunciada que as demais; margem ventral quase reta; extremidades valvares arredondadas, amplamente dilatadas, destacadas do corpo valvar; nódulos terminais nas extremidades, quase imperceptíveis; estrias transapicais paralelas a levemente radiadas em direção às extremidades. Em MEV observa-se uma helictoglossa muito próxima da extremidade valvar. Rafe curvada, estendendo-se até o eixo apical, na superfície valvar externa. Medidas: 22-23,4 $\mu \mathrm{m}$ compr.; 6,6-7,0 $\mu \mathrm{m}$ larg.; r c/1 3,5; estrias 10-13 em $10 \mu \mathrm{m}$; aréolas 40 em $10 \mu \mathrm{m}$.

Material examinado: BRASIL. Rio GRANDE do Sul: Capivari do Sul, banhado entre Lagoa do Capivari e Lagoa do Casamento, 05-V-2003, V.R. Werner (HAS104096, lâm. 5811, HAS104092, lâm. 5809).

Eunotia submonodon Hust., in Schmidt, Atlas Diatom.Kunde, pl. 288, fig. 18. 1874-1959.

Figura 37

Valvas com margem dorsal convexa; margem ventral levemente côncava; extremidades valvares arredondadas, não destacadas do corpo valvar; nódulos terminais nas extremidades; estrias transapicais levemente radiadas, mais concentradas nas extremidades. Medidas: $36 \mu \mathrm{m}$ compr.; $10 \mu \mathrm{m}$ larg.; r c/13,6; estrias 8 (centro) em $10 \mu \mathrm{m}$ e 14 (extremidades) em $10 \mu \mathrm{m}$.

Material examinado: BRASIL. Rio GRANDE Do Sul: Mostardas, Lagoa dos Gateados Sul, 09-V-2003, L.C. Torgan (HAS104183, lâm. 5769).

Eunotia subrobusta Hust., in Schmidt Atlas DiatomKunde, pl. 286, figs. 2-8. 1874-1959.

Figura 38

Valvas com margem dorsal fortemente convexa, apresentando quatro ondulações; margem ventral fortemente côncava; extremidades valvares arredondadas, levemente voltadas para a margem dorsal; nódulos terminais nas extremidades; estrias transapicais paralelas, com aréolas conspícuas. Medidas: $57 \mu \mathrm{m}$ compr.; $7 \mu \mathrm{m}$ larg.; r c/1 8,1; estrias $10 \mathrm{em} 10 \mu \mathrm{m}$. 
O exemplar analisado concorda com a circunscrição da espécie, entretanto, possui a margem ventral mais fortemente côncava e as ondulações da margem dorsal mais atenuadas assemelhando-se ao exemplar ilustrado por Frenguelli (1931-1933), sem apresentar, porém, nítida intumescência na região mediana da margem ventral.

Material examinado: BRASIL. Rio Grande do Sul: Palmares do Sul, banhado Fazenda Rincão do Anastácio, 07-V-2003, V.R. Werner (HAS104121, lâm. 5814).

Eunotia tecta Krasske, Arch. Hydrobiol., 35:364, pl. 10, figs. 42-43. 1939.

Figura 39

Valvas com margem dorsal convexa, apresentando três ondulações; margem ventral côncava; extremidades valvares arredondadas a levemente truncadas, levemente voltadas para a margem dorsal; nódulos terminais nas extremidades; estrias transapicais paralelas a levemente radiadas em direção às extremidades. Medidas: 32,535,2 $\mu \mathrm{m}$ compr.; 7-8 $\mu \mathrm{m}$ larg.; $\mathrm{r} \mathrm{c} / 1$ 4,4-4,6; estrias 10-13 em $10 \mu \mathrm{m}$.

Os exemplares diferem das ilustrações contidas na obra original quanto ao formato das extremidades, que nestas encontram-se mais arredondadas. Porém, analisando o trabalho de Lange-Bertalot et al. (1996), que apresenta fotomicrografias do material-tipo da coleção de Krasske oriundo do Chile, nota-se que as populações chilenas são bastante semelhantes aos exemplares analisados, dando condições para que o material seja identificado como pertencente ao táxon em questão. Comparando-os ao material encontrado por Metzeltin et al. (2005) no Rio Tacuari, Uruguai, este difere quanto à morfologia por possuir as ondulações da margem dorsal com formato angular. Citada como $E$. praerupta Ehr. var. tridentata (Ehr.) Freng. por Torgan \& Delani (1988) no Banhado Grande.

Material examinado: BRASIL. Rio GRANDE Do SuL: Tapes, lagoinha entre dunas, 04-VI-2003, L.C. Torgan \& V.R. Werner (HAS104230, lâm. 5834A e 5955); banhado entre dunas, 04-VI-2003, L.C. Torgan \& V.R. Werner (HAS104234).

Eunotia tridentula Ehr. var. tridentula, Abh. Preuss. K. Akad. Wiss. Phys.-math. K1. 1841: 414, pl. 2, fig. 14. 1843.

Figuras 40, 65

Valvas com margem dorsal convexa, apresentando três ondulações, sendo a central mais pronunciada; margem ventral levemente côncava; extremidades valvares atenuado-arredondadas; nódulos terminais nas extremidades; estrias transapicais paralelas, com aréolas às vezes conspícuas. Em MEV observa-se uma rimoportula presente em uma das extremidades da valva, no eixo apical, de posição oblíqua em relação à helictoglossa. Medidas: 51,6-61 $\mu \mathrm{m}$ compr.; 7,5-8,4 $\mu \mathrm{m}$ larg.; $\mathrm{r}$ c/1 6,1-8,1; estrias 10-11 em 10; aréolas 40 em $10 \mu \mathrm{m}$.

A obra original de Ehrenberg (1841-1843) não oferece condições de analisar as características diacríticas da espécie, além de não mencionar as dimensões valvares e número de estrias. O material foi identificado com base em Lange-Bertalot et al. (1996) que apresenta fotomicrografias de exemplares das coleções de Krasske e de Cleve \& Möller, bem como do material-tipo. Metzeltin et al. (2005) observaram, em diversas regiões do Uruguai, populações semelhantes ao material analisado.

O táxon foi citado para o Rio Grande do Sul como Eunotia pyramidata Hust. var. pyramidata por Torgan \& Delani (1988) no Banhado Grande, Torgan (1985) na represa de Águas Belas, Torgan \& Aguiar (1978) no Lago Guaíba, Torgan et al. (1993) em Sphagnum, no Parque Estadual de Itapuã. Analisando o material-tipo, observa-se que se trata do mesmo táxon. Manteve-se o nome de E. tridentula Ehr. por ser o epíteto mais antigo e válido de acordo com as normas do Código Internacional de Nomenclatura Botânica.

Material examinado: BRASIL. Rio GRANDE Do Sul: Capivari do Sul, banhado entre Lagoa do Capivari e Lagoa do Casamento, 05-V-2003, V.R. Werner (HAS104092, lâm. 5809); 05-VI-2003, V.R. Werner (HAS104096, lâm. 5811); Tapes, lagoinha entre dunas, 04-VI-2003, L.C. Torgan \& V.R. Werner (HAS104230, lâm. 5955); Lagoa Redonda, 03-XII-2003, L. Cardoso (HAS104455, lâm. 5867).

Eunotia tridentula var. monodon (Krasske) Nörpel-Sch., in Lange-Bert. et al., Iconogr. Diatomol., 3: 332, pl. 65, figs. 16-23. 1996.

Figuras 41, 66

Valvas com margem dorsal convexa; margem ventral levemente côncava; extremidades valvares arredondadas, levemente destacadas do corpo valvar; nódulos terminais nas extremidades; estrias transapicais paralelas. Em MEV observa-se uma helictoglossa muito próxima da extremidade valvar. Medidas: 15,6-31,2 $\mu \mathrm{m}$ compr.; 5,4-6,7 $\mu \mathrm{m}$ larg.; r c/1 2,8-5,2; estrias 10-17 em $10 \mu \mathrm{m}$; aréolas $30 \mathrm{em} 10 \mu \mathrm{m}$.

Lange-Bertalot et al. (1996), analisando o lectotipo de E. pyramidata var. monodon Krasske da coleção de 

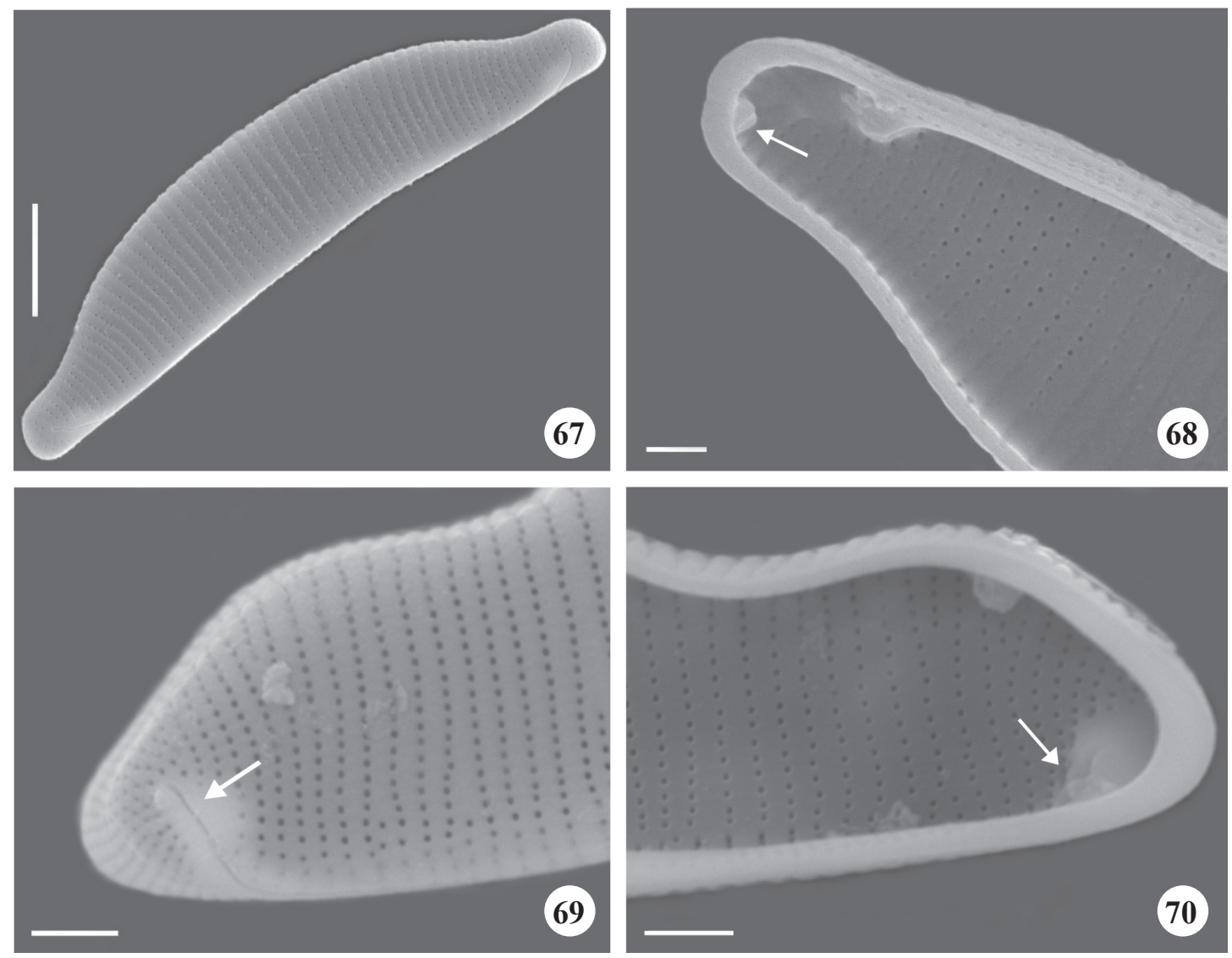

Figuras 67-70. Ilustrações em MEV. 67, 68. E. veneris. 67. Vista valvar externa. 68. Vista interna mostrando a rimoportula (seta). 69, 70. E. zygodon. 69. Extremidade externa mostrando a rafe com nódulo lobado (seta). 70. Extremidade interna mostrando a helictoglossa (seta). Barra $=5 \mu \mathrm{m}(67), 1 \mu \mathrm{m}(68-70)$.

Figures 67-70. Illustrations in SEM. 67, 68. E. veneris. 67. External view of the valve. 68. Internal view showing the rimoportula (arrow). 69, 70. E. zygodon. 69. External pole showing the raphe with lobed terminal nodules (arrow). 70. Internal pole showing the helictoglossa (arrow). Bar $=5 \mu \mathrm{m}(67), 1 \mu \mathrm{m}(68-70)$.

Krasske, transferiram a variedade para a espécie em questão. A espécie foi citada como E. pyramidata Hust. var. monodon Krasske por Laudares-Silva (1987) no arroio do Faxinal e Torgan et al. (1993) em Sphagnum sp. no Parque Estadual de Itapuã.

Material examinado: BRASIL. Rio Grande do Sul: Capivari do Sul, banhado entre Lagoa do Capivari e Lagoa do Casamento, 05-V-2003, V.R. Werner (HAS104096, lâm. 5811, HAS104092, lâm. 5808 e 5809); Tapes, Lagoa Redonda, 03-XII-2003, L. Cardoso (HAS104455, lâm. 5867).

Eunotia veneris (Küt.) De Toni, Syll. alg. 2(2): 794. 1892.

Figuras 43, 67-68

Valvas com margem dorsal convexa; margem ventral reta; extremidades valvares dorsalmente subcapitadas, destacadas do corpo valvar; nódulos terminais afastados das extremidades; estrias transapicais paralelas. Em MEV observa-se uma rimoportula presente em uma das extremidades da valva, acima do eixo apical, próxima à margem dorsal, de posição oblíqua em relação à helictoglossa. Medidas: 31,5-45,5 $\mu \mathrm{m}$ compr.; 5,3$6,3 \mu \mathrm{m}$ larg.; $\mathrm{r} \mathrm{c} / 1$ 5,0-8,3; estrias 13-20 em $10 \mu \mathrm{m}$; aréolas $40 \mathrm{em} 10 \mu \mathrm{m}$.

Esta espécie é muitas vezes confundida com Eunotia incisa W. Smith ex Gregory e E. pirla Carter \& Flower, devido ao formato das valvas e das extremidades serem semelhantes, o que faz necessário um estudo mais aprofundado em nível de microscopia eletrônica envolvendo estes táxons.

Material examinado: BRASIL. Rio GRANDE DO Sul: Tapes, banhado com Sphagnum, 04-VI-2003, L.C. Torgan \& V.R. Werner (HAS104221, lâm. 5831); 03-XII2003, L. Cardoso (HAS104440, lâm. 5869); lagoinha 
entre dunas, 04-VI-2003, L.C. Torgan \& V.R. Werner (HAS104230, lâm. 5955); Lagoa das Capivaras, 03-XII2003, S.M. Alves-da-Silva (HAS104435).

Eunotia vumbae Choln., Port. Acta biol. 4(3-4): 212, figs. 54, 55, 56-58. 1954.

Figura 42

Valvas com margem dorsal convexa, margem ventral côncava; extremidades valvares arredondadas, não destacadas do corpo valvar; nódulos terminais inconspícuos; estrias transapicais paralelas a radiadas em direção às extremidades. Medidas: $15,5 \mu \mathrm{m}$ compr.; $6 \mu \mathrm{m}$ larg.; $\mathrm{r} \mathrm{c} / 12,5$; estrias $14 \mathrm{em} 10 \mu \mathrm{m}$.

O exemplar observado difere do material-tipo, oriundo da região da floresta de Vumba ao sul da Rodésia, África (Chlonoky 1954), pelo menor tamanho, pois o comprimento mínimo registrado pelo autor foi de $20 \mu \mathrm{m}$. Eunotia vumbae Choln. diferencia-se de E. rabenhorstii Cleve var. monodon Grunow et Cleve pelo formato das extremidades valvares e ausência de ondulação na margem dorsal.

Material examinado: BRASIL. Rio GRANDE Do Sul: Capivari do Sul, banhado entre Lagoa do Capivari e Lagoa do Casamento, 05-V-2003, V.R. Werner (HAS104096, lâm. 5811).

Eunotia yberai Freng., An. Mus. Hist. Natural (37): 446, pl. 8, fig. 12. 1931-1933.

Figura 44

Valvas com margem dorsal levemente convexa; margem ventral reta; extremidades valvares dorsalmente subcapitadas, cuneadas, destacadas do corpo valvar; nódulos terminais nas extremidades; estrias transapicais paralelas na região mediana e levemente radiadas nas extremidades, algumas mais curtas que as demais. Medidas: $65 \mu \mathrm{m}$ compr.; $13 \mu \mathrm{m}$ larg.; $\mathrm{r}$ c/1 5,0; estrias 8 (no centro) e 10 (nas extremidades) em $10 \mu \mathrm{m}$.

Material examinado: BRASIL. Rio GRANDE Do SuL: Mostardas, Lagoa dos Gateados Norte, 08-V-2003, V.R. Werner (HAS104140, lâm. 5737).

Eunotia zygodon Ehr., Phys. Abh. K. Akad. Wiss. Berlin, p. 415 , pl. 2, fig. 6.1843.

Figuras 45, 69-70

Valvas com margem dorsal convexa, apresentando duas ondulações; margem ventral côncava; extremidades valvares cuneado-arredondadas; nódulos terminais trilobados, próximos das extremidades; estrias transapicais paralelas na região mediana e nitidamente radiadas nas extremidades, com aréolas inconspícuas. Em MEV, vista externa, a rafe se apresenta inclinada em direção às extremidades, ultrapassando o eixo apical. Medidas: 43,4-120 $\mu \mathrm{m}$ compr.; 10-22 $\mu \mathrm{m}$ larg.; $\mathrm{r} \mathrm{c} / 1$ 5,0-5,9; estrias 12-16 (no centro) em $10 \mu \mathrm{m}$; aréolas 25-30 em $10 \mu \mathrm{m}$.

Material examinado: BRASIL. Rio GRANDE do Sul: Tapes, Lagoa das Capivaras, 04-VI-2003, V.R. Werner (HAS104215, lâm. 5782); 03-XII-2003, L. Cardoso (HAS104435); lagoinha entre dunas, 04-VI-2003, L.C. Torgan \& V.R. Werner (HAS104230, lâm. 5833 e 5834A); banhado entre dunas, 04-VI-2003, L.C. Torgan \& V.R. Werner (HAS104234, lâm. 5815 e 5818); 03-XII2003, L. Cardoso (HAS104449, lâm. 5863); Mostardas, Lagoa dos Gateados Sul, 31-X-2003, S.M. Alves-da-Silva (HAS104403, lâm. 5874).

Riqueza e constância dos táxons e relação com as condições ambientais - Os ambientes lacustres das áreas da Lagoa do Casamento e do Butiazal de Tapes apresentaram-se em geral levemente ácidos ( $\mathrm{pH}$ 6,26,9 ), com temperatura que variou entre 14,0 e $29,8{ }^{\circ} \mathrm{C}$. A condutividade da água apresentou valores mais altos $\left(>80 \mu \mathrm{S} \mathrm{cm}^{-1}\right)$ nos ambientes da Lagoa do Casamento e mais baixos $\left(<70 \mu \mathrm{S} \mathrm{cm}^{-1}\right)$ nos ambientes da área do Butiazal de Tapes. Os banhados, tanto da área da Lagoa do Casamento como do Butiazal de Tapes, apresentaram maior riqueza de espécies de Eunotia. A ocorrência de vegetação marginal mais abundante no banhado entre a Lagoa Capivari e Casamento e valores mais baixos de $\mathrm{pH}(4,3$ e 5,4$)$ no banhado com Sphagnum foram provavelmente condições que favoreceram a riqueza deste gênero. Krammer \& Lange-Bertalot (1991) já mencionaram que, em "Sphagnum bogs" e outras áreas alagadas ricas em matéria orgânica comumente contêm uma rica diversidade de Eunotiaceae, embora as interações bióticas não tenham sido detalhadas. Segundo Round et al. (1990) Eunotia é um gênero particularmente abundante no epifíton e metafíton, portanto, era de esperar uma maior riqueza de espécies junto a vegetação de banhados.

Com relação ao índice de constância das espécies nas áreas de estudo, Eunotia flexuosa e E. didyma foram consideradas constantes na área da Lagoa do Casamento, sendo que a primeira foi bastante representativa, estando presente em $100 \%$ dos ambientes amostrados. Eunotia itapuana e E. pectinalis foram frequentes em ambas as áreas, tendo sido encontradas nos diferentes ambientes de ambas as áreas. Eunotia maior, E. pseudosudetica e $E$. rabenhorstii var. monodon foram consideradas comuns 
na área da Lagoa do Casamento, enquanto Actinella guianensis, Eunotia asterionelloides, E. bilunaris, E. camelus, E. didyma, E. indica, E. pseudoindica, E. tecta, E. tridentula var. tridentula e E. vumbae foram comuns na área do Butiazal de Tapes. Cabe mencionar que, dentre as espécies consideradas raras em cada área, Eunotia asterionelloides, E. paludosa, E. rabenhorstii var. triodon, E. subrobusta, E. tridentula var. tridentula foram exclusivas de banhado.

Distribuição geográfica dos táxons - Eunotia camelus e E. pectinalis são espécies com ampla distribuição no Estado, pois foram mencionadas em levantamentos efetuados na região da Depressão Central (Torgan 1985, Torgan \& Delani 1988), Litoral (Laudares-Silva 1987), Alto Uruguai (Callegaro et al. 1993) e Plataforma Continental (Rosa \& Aguiar 1975).

A grande maioria (Eunotia bidens, E. didyma, E. flexuosa, E. pseudoindica, E. itapuana, E. maior, E. naegelii, E. tridentula var. monodon, E. rabenhorstii var. monodon, E. rabenhorstii var. triodon e E. subrobusta) tinha sido registrada somente nas regiões da Depressão Central e Litoral, onde os estudos foram intensamente realizados.

Eunotia bilunaris, E. tridentula var. tridentula, E. vumbae, E. yberai e E. zygodon foram citadas somente na Depressão Central (Aguiar \& Martau 1979, Torgan \& Delani 1988) e Encosta Inferior do Nordeste (Oliveira \& Schwarzbold 1998), sendo pela primeira vez registradas na região Litoral, vindo desta forma ampliar o conhecimento da família na Planície Costeira do Rio Grande do Sul.

Agradecimentos - À Coordenação de Aperfeiçoamento de Pessoal de Nível Superior (Capes) e ao Conselho Nacional de Desenvolvimento Científico e Tecnológico (CNPq) pelas Bolsas de Mestrado e de Produtividade à Pesquisa à primeira e à segunda autora, respectivamente. Ao Centro de Microscopia Eletrônica da UFRGS, por disponibilizar o uso do microscópio eletrônico de varredura. Aos funcionários da Seção de Geoprocessamento do Museu de Ciências Naturais/ FZB pelo apoio técnico. À Carolina Randazzo de Oliveira pelo auxílio com Bolsa de Apoio Técnico do CNPq.

\section{Referências bibliográficas}

AGUIAR, L. \& MARTAU, L. 1979. Diatomáceas de lagos do Parque Zoológico, Rio Grande do Sul, Brasil. Iheringia. Série Botânica 25:27-110.

BICUDO, D.C., DE-LAMONICA-FREIRE, E.M. \& LIMA, D. 1995. Ficoflórula do Pantanal de Poconé, estado de Mato Grosso, Brasil: Centrales e Eunotiaceae (Bacillariophyceae). Hoehnea 22:165-182.
BICCA, A.B. \& TORGAN, L.C. 2009. Novos registros de Eunotia Eherenberg (Eunotiaceae-Bacillariophyta) para o Estado do Rio Grande do Sul e Brasil. Acta Botanica Brasilica 23:427-435.

CALLEGARO, V.L.M. 1995. Diatomáceas da turfeira de Águas Claras, Rio Grande do Sul, Brasil: gênero Eunotia Ehrenberg. Revista Brasileira de Biologia 55:369-382.

CALLEGARO, V.L.M., SILVA, K.R.L.M. \& SALOMONI, S.E. 1993. Flórula diatomológica de ambientes lênticos e lóticos do Parque Florestal Estadual do Turvo, Rio Grande do Sul, Brasil. Iheringia. Série Botânica 43:89-134.

CHOLNOKY, B.J. 1954. Diatomeen aus Süd-Rhodesien. Portugaliae Acta Biologica 4:197-233.

EHRENBERG, C.G. 1841-1843. Verbreitung und Einfluss des mikroskopishen Lebens in Süd un North America. Abhandlungen der Königlichen Akademie der Wissenschaften zu Berlin 1:291-445.

FRENGUELLI, J. 1931-1933. Contribuciones al conocimiento de las Diatomeas Argentinas. VII Diatomeas de la Región de los esteros del Iberá (en la Provincia de Corrientes). Anales del Museo Argentino de Historia Natural 37:365-475.

FRENGUELLI, J. 1941. Contribuciones al conocimiento de las Diatomeas Argentinas XVI. Diatomeas del Río de La Plata. Revista del Museo de La Plata 3:213-334.

GRUNOW, A. 1865. Über die Von Herrn Gerstenberger in Rabenhorst's Decaden ausgegebenen Süsswasser Diatomaceen und Desmidiaceen von der Insel Banka, nebst Untersuchungen über die Gattungen Ceratoneis und Frustulia. Rabenhorst Beitrage, Leipizig. Plate 1-2. Microficha IDC.

KOCIOLEK, J.P. 2000. Valve ultratructure of some Eunotiaceae (Bacillariophyceae) with comments on the evolution of the raphe system. Proceedings of the California Academy of Sciences 52:11-21.

KOCIOLEK, J.P., LYON, D. \& SPAULDING, S. 2001. Revision of the South American species of Actinella. In Lange-Bertalot-Festschrift. (R. Jahn, J.P Kociolek, A. Witkowski \& P. Compère, eds.). A.R.G. Gantner Orlag Ruggell, Liechtenstein, p.131-165.

KOCIOLEK, J.P. \& SPAULDING, S. 2003. Eunotioid and asymmetrical naviculoid diatoms. In Freshwater algae of North America. Ecology and classification (J.D. Wehr \& R.G.F. Sheath, eds.). Academic Press Elsevier Science, London, p.655-668.

KRAMMER, K. \& LANGE-BERTALOT, H. 1991. Bacillariophyceae:Centrale, Fragilariaceae, Eunotiaceae. In Susswasserflora von Mitteleuropa (H. Etll, J. Gerloff, H. Heynig \& D. Mollenhauer, eds.). Gustav Fisher Verlag, Stuttgart, p.1-576.

LANGE-BERTALOT, H., KÜLBST, K., LAUSER, T., NÖRPEL-SCHEMPP, M. \& WILLMANN, M. 1996. DiatomtaxaintroducedbyGeorgKrasske-documentation and revision. In Iconographia Diatomologica annotated diatom micrographs (H. Lange-Bertalot, ed.). Koeltz Scientific Books, Stuttgart, v.3, p.1-358. 
LAUDARES-SILVA, R. 1987. Estudo taxonômico das diatomáceas (Bacillariophyceae) coletadas no arroio do Faxinal (Sanga de Água Boa), Torres, Rio Grande do Sul, Brasil. Insula 17:3-184.

LE COHU, R. 1993. Cingulum et système raphéen chez Eunotia arcus et Eunotia bilunaris (Bacillariophycées). Cryptogamie Algologie 14:11-19.

METZELTIN, D. \& LANGE-BERTALOT, H. 1998. Tropische Diatoms of South America, 1. In Iconographia Diatomologica, annotated diatom micrographs (H. Lange-Bertalot, ed.). Koeltz Scientific Books, Stuttgart, v.5.

METZELTIN, D., LANGE-BERTALOT, H. \& GARCÍARODRIGUEZ, F. 2005. Diatoms of Uruguay. In Iconographia Diatomologica. Annotated diatom micrographs. (H. Lange-Bertalot, ed.). Koeltz Scientific Books, Stuttgart, v.15, p.1-736.

METZELTIN, D. \& LANGE-BERTALOT, H. 2007. Tropical Diatoms of South America II. Special remarks on biogeographic disjunction. In Iconographia Diatomologica. Annotated diatom micrographs $(\mathrm{H}$. Lange-Bertalot, ed.). Koeltz Scientific Books, Stuttgart, v.18, p.1-877.

OLIVEIRA, M.A. \& SCHWARZBOLD, A. 1998. Influência de fatores abióticos sobre a estrutura da comunidade perifítica de limnotopos da Bacia do Arroio Sampaio, Mato Leitão, Rio Grande do Sul, Brasil. Iheringia. Série Botânica 51:45-72.

OLIVEIRA, M.A., TORGAN, L.C., LOBO, E.A. \& SCHWARZBOLD, A. 2001. Association of periphytic diatom species of artificial substrate in lotic environments in the Arroio Sampaio basin, RS, Brazil: relationships with abiotic variables. Brazilian Journal of Biology 61:523-540.

ROSA, Z. \& AGUIAR, L. 1975. Diatomáceas da costa do Rio Grande do Sul, Brasil: 1 - Praia do Cassino - Rio Grande. Iheringia. Série Botânica 21:103-128.

ROUND, F.E., CRAWFORD, R.M. \& MANN, D.G. 1990. The diatoms: biology and morphology of the genera. Cambridge University Press, New York.

SCHMIDT, A., FRICKE, F., HEIDEN, H., MÜLLER, O. \& HUSTEDT, F. 1874-1959. Atlas der Diatomaceenkunde. Zentralantiquariat, Leipzig.

SOUZA, M.G.M. \& MOREIRA-FILHO, H. 1999. Diatoms (Bacillariophyceae) of two aquatic macrophyte Banks from Lagoa Bonita, Distrito Federal, Brazil, I: Thalassiosiraceae and Eunotiaceae. Bulletin Du Jardin Botanique Nacional Belgique 67:259-278.

TORGAN, L.C. 1983. Uma nova variedade de Eunotia didyma Hustedt ex Zimmermann (Bacillariophyceae) do Sul do Brasil. Iheringia. Série Botânica 31:31-36.
TORGAN, L.C. 1985. Estudo taxonômico de diatomáceas (Bacillariophyceae) da represa de Águas Belas, Viamão, Rio Grande do Sul, Brasil. Iheringia. Série Botânica 33:17-104.

TORGAN, L.C. \& AGUIAR, L. 1978. Diatomáceas do "Rio Guaíba", Porto Alegre, Brasil. Iheringia. Série Botânica 23:19-63.

TORGAN, L.C., ALVES DA SILVA, S.M., WERNER, V.R., ROSA, Z.M., CARDOSO, L.S., RODRIGUES, S.C., DOS SANTOS, C.B., PALMA, C.B., BICCA, A.B., FORTUNA, J.R., WEBER, A.S. \& MATINS, M.D. 2006. Ficoflora. In Biodiversidade da região dos Butiazais de Tapes e da Lagoa do Casamento, Planície Costeira do Rio Grande do Sul (F.G. Becker, R.A. Ramos \& L.A. Azevedo, orgs.). Ministério do Meio Ambiente, Fundação Zoobotânica do Rio Grande do Sul, Brasília, p.112-129.

TORGAN,L.C.,BECKER,V.\&PRATES,H.M.1999.Checklist das diatomáceas (Bacillariophyceae) de ambientes de águas continentais e costeiros do estado do Rio Grande do Sul. Iheringia, Série Botânica 52:89-144.

TORGAN, L.C. \& DELANI, O.M. 1988. Estudo taxonômico de diatomáceas (Bacillariophyceae) do "Complexo Banhado Grande", Rio Grande do Sul, Brasil: representantes do gênero Eunotia Ehrenberg. Iheringia, Série Botânica 38:81-107.

TORGAN, L.C., PAULA, M.C.F. DE. \& DELANI, O.M. 1993. Diatomáceas (Bacillariophyceae) perifíticas em Sphagnum recurvum P. Beauv., no Parque Estadual de Itapuã, Rio Grande do Sul, Brasil: taxonomia e aspectos ecológicos. Caderno de Pesquisa. Série Botânica 5:109-142.

TORGAN, L.C., SALOMONI, S.E. \& BICCA, A.B. 2009. Diatomáceas sobre Limnoperna fortunei (Dunker), molusco introduzido no Lago Guaíba, Sul do Brasil. Revista Brasileira de Botânica 32:23-31.

VAN DER WERFF, A. 1955. A new method of concentrating and cleaning diatoms and other organisms. Verlandlungen der Internationalen Verinigung der Limnologie 55: 276-277.

WILLIAMS, D.M. \& REID, G. 2006. Amphorotia nov. gen., a new genus in the family Eunotiaceae (Bacillariophyceae), based on Eunotia clevei Grunow in Cleve \& Grunow. In Diatom Monographs (A. Witkowski, ed.). G. Gantner Verlag K.G., Ruggell, v.6, p.1-153.

ZIMMERMANN, C.S.J. 1915. Contribuição para o estudo das diatomáceas dos Estados Unidos do Brasil III. Brotéria, Série Botânica 12:65-71.

ZIMMERMANN, C.S.J. 1916. Contribuição para o estudo das diatomáceas dos Estados Unidos do Brasil V. Brotéria. Série Botânica 14:130-157. 